\title{
The social correlates and linguistic processes of lexical borrowing and assimilation*
}

\author{
SHANA POPLACK, DAVID SANKOFF, and CHRISTOPHER MILLER
}

\section{Abstract}

This paper represents a comprehensive study of English loanword usage in five diverse francophone neighborhoods in the national capital region of Canada. Twenty thousand loan tokens extracted from informal conversations with 120 speakers are analyzed for degree of linguistic integration into French and social assimilation by the francophone community. Attestation histories of English forms in Canadian and European French are compared with current usage frequencies and various measures of integration. We distinguish two basic patterns of borrowing - nonce and established which show similar linguistic characteristics, contrasting thereby with unambiguous code-switches. We trace the differential effects of environmental (majority/minority status of French in the neighborhood), individual (degree of bilingual proficiency), and sociodemographic (occupational class, age, etc.) factors on overall borrowing rates and patterns of use of different types of loanwords. With respect to overall rate of borrowing, social class membership is found to be a better predictor than either environmental effects or individual bilingual proficiency. In terms of borrowing pattern, environmental factors are paramount, suggesting that borrowing behavior is acquired, and not merely a function of lexical need.

\subsection{Introduction}

Innovative usage of vocabulary by the speakers of a language, the success or failure of these innovations in achieving currency and acceptance in the speech community, and the socially conditioned variation and change in their use are general processes of lexical dynamics which have counterparts in the borrowing and assimilation of words from other languages. Thus the first uses of a borrowing, possibly but not necessarily by a bilingual, to specify some culturally or technologically novel concept, or 
to refer to some established notion in a new way, is but a special case of the emergence of a new word-meaning relationship. It is comparable with the introduction of acronyms and other neologisms, and with monolingual processes such as the semantic extension of the reference of some existing lexical item, the formation of a new compound, the nominalization of a verb or adjective, or analogical use of derivational morphology.

Similarly, the processes by which a borrowed word begins to circulate in the community beyond the individual(s) or small circle that introduced it are conditioned by functional, aesthetic, and social factors similar to those that determine the spread (or obsolescence) of other lexical introductions.

The borrowing process, of course, is different in some respects from monolingual lexical change. For example, the phonological shape and the morphological composition of borrowed words are not, at least initially, likely to coincide exactly with host language patterns. The agents of introduction and, to some extent, transmission of borrowings within the community are more likely to be bilinguals or those in direct contact with the donor language and/or culture, whereas the innovation and propagation of other lexical novelties may, to a greater extent, be due to other subgroups within the community, such as the intellectual establishment (see Bourdieu and Boltanski 1975), schools, the media, minorities imbued with some measure of cultural prestige, the youth subculture, or the world of science and technology. Note, however, that the latter two groups are often precisely those with most contact with the other language, especially if it is English, and hence could very well be those primarily responsible for borrowing and transmission of loanwords.

A major goal of this paper is to investigate what features of borrowing and integration are particular to the community under study, which aspects are of interest for universal theories of language contact, and which others can provide insight into general (monolingual) patterns of lexical dynamics.

Study of the usage properties of borrowings in bilingual discourse is notoriously complex. Items may be borrowed from another language once and never heard again, or they may be used with great regularity. A word may follow $L_{1}$ or $L_{2}$ patterns, depending on the ability and/or intent of the speaker, as well as on other aspects of the context. In isolation it reveals nothing about the processes of assimilation, social or linguistic. In order to measure degree of linguistic integration it is necessary for a word to occur frequently enough to discover whether it is used in a patterned way.

Gathering enough data.for the systematic study of the use of borrowed words in a speech community is inherently very difficult. Tokens of these 
words are typically rare in monolingual discourse, so that several hours of speech will yield only a few dozen, most of which occur only once. In certain contexts, of course, and for certain topics of conversation, there will be some set of borrowings which are used repeatedly, but the imposition of contextual or topical restrictions would vitiate the comprehensiveness and representativity of any investigation attempting to give a general characterization of borrowing and integration.

Previous studies have thus had to resort to artificial methods of data elicitation (Mackey 1970; Hasselmo 1969; Poplack and Sankoff 1984), or to analysis of only a few isolated naturally occurring borrowings (Mougeon et al. 1985b), or, most commonly, to anecdotal lists of borrowed words (for example, Nash 1970; Bowen 1975). Though these may provide some indication of the borrowing processes that interest us, they only constitute indirect evidence about spontaneous speech behavior on the part of bilinguals.

The research reported in this paper transcends this sort of limitation in being based on a massive corpus of speech dealing with a broad inventory of subjects of everyday life, recorded from a scientifically selected sample of speakers in a well-defined speech community. Though borrowings constitute less than one percent of their total lexicon, ${ }^{1}$ this miniscule fraction still represents 20,000 tokens of some 2000 different borrowed types, a uniquely rich body of data in this field of study.

This corpus was collected as part of an ongoing sociolinguistic investigation of the French spoken in the national capital region of Canada (Ottawa and Hull) and the effects on it of contact with English (Poplack i.p.). The urban Ottawa-Hull complex is an ideal site for a study of this issue since it contains francophone communities whose status as majorityor minority-language speakers varies according to their location with respect to the border between Ontario (French minority language) and Quebec (French majority language), which bisects the region. The sample is constructed according to sociolinguistic principles (for example, Labov 1970, 1971, 1984; Sankoff and Sankoff 1973; G. Sankoff 1974); hence it is most appropriate for investigating a wide range of theoretical problems about the dynamics of the borrowing process within the speech community. Thus questions of generational differences in borrowing and of the evolution over time of the stock of English-origin loanwords can be addressed by taking into account speakers' ages. Class-based stigmatization of borrowing may be distinguished from the demographic and political dominance of French as a factor in loanword avoidance, through comparison of the behavior of individuals of different occupational classes within various Ottawa (Ontario) versus Hull (Quebec) neighborhoods. Contrasting different neighborhoods can also help us evaluate the 
roles of geographical isolation and contiguity in loanword diffusion and the relative importance of individual bilingual competence versus environmental influences on the use of borrowings. These and other factors have all been postulated as key elements in favoring or hindering the introduction and spread of foreign vocabulary, and it is only by empirically assessing the relative importance of each on a sufficiently large data base that we can hope to confirm or refute any of the various mutually contradictory theoretical claims.

Prior to the sociolinguistic analysis, we examine the integration or assimilation of the English-origin words in our data base, both in terms of French linguistic (phonological, morphological, and syntactic) categories, and in terms of their historical persistence (versus recency), their level of usage within the community, as measured by overall frequency, and their dispersion across semantic fields. Between the time an English word first appears in French discourse, and the time (if ever) it qualifies for dictionary (or other word-list) status, many changes in form, usage, and acceptability occur. There is no natural way of identifying a discrete point within this interval before which the word is not an integrated loan, and after which it suddenly becomes one. We can of course distinguish between those that occur only once in our corpus ('nonce' borrowings) and those used by many speakers (widespread loans), but a priori we cannot take for granted that this purely operational distinction correlates either with the degree of linguistic assimilation of the word or with its history of attestation as a loanword in the language.

This focus on borrowing as a process over time rather than as a sudden transition enables us to contribute to a coherent analytical framework for bilingual discourse. We will attempt to determine to what extent the properties of nonce borrowings, as abstracted from their quantitative behavior, are weaker or incipient versions of those of widespread, established loans, or whether they tend to share some of the characteristics of code-switches. One contribution of this research, then, will be the validation of distributional and contextual criteria for distinguishing between borrowings and code-switches. This is essential to the operational establishment of data sets on either of these phenomena with a minimum of contamination from the other.

Many of the analytical methods we apply to loanwords could also be applied to other areas of the lexicon. This is particularly the case for the sociolinguistic characterization of the spread of new lexical items or usages in various subgroups of the community, but it is also true. for our procedures for measuring changes in their phonological form, morphology, and syntactic role. 


\subsection{Data and methods}

Five core francophone neighborhoods in the Ottawa-Hull region, each with differential amounts of environmental exposure to English, ${ }^{2}$ depicted in Figure 1, were sampled according to strict survey procedures.

The three Ottawa neighborhoods, the West End, Basse-Ville, and Vanier, although all basically working-class areas, differ widely in the proportion of their residents claiming English mother-tongue status. The West End contains fewer French than English speakers, whereas Vanier contains three times as many francophones as anglophones, with BasseVille falling somewhere in between. Vanier, as we shall see, is more middle-class than the other two, while Basse-Ville is a heterogeneous neighborhood undergoing gentrification. The West End is geographically isolated from the other francophone concentrations and is socially and culturally somewhat more marginal. On the Hull side of the Ottawa river, which is also the provincial border between Quebec and Ontario, the working-class neighborhood of Vieux Hull contrasts with middle-class Mont Bleu, though both have negligible anglophone populations.

Twenty-four individuals were sampled from each neighborhood, equally divided according to age and sex and characterized according to socioeconomic status, educational level, and degree of proficiency in English. ${ }^{3}$ Using participant-observer techniques, local in-group interviewers recorded a large body of informal French conversational data from these speakers, yielding a data base of over two million words, which was subsequently transcribed onto computer files and concordanced. ${ }^{4}$ These conversations contained many examples of English-origin words; those identified as potential borrowings will be the focus of study here.

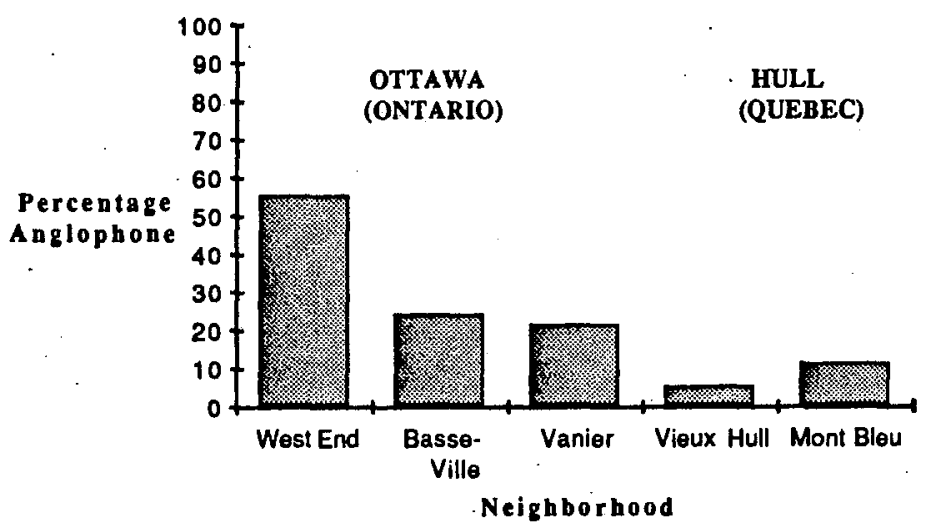

Figure 1. English in the environment: proportion of anglophones resident in the five neighborhoods of the Ottawa-Hull corpus 


\subsection{Borrowing}

Lexical borrowing involves the incorporation of individual $\mathrm{L}_{2}$ words (or compounds functioning as single words) into discourse of $L_{1}$, the host or recipient language, usually phonologically and morphologically adapted to conform with the patterns of that language, and occupying a sentence slot dictated by its syntax. The status of 'loanword', however, is traditionally conferred only on words which, in addition, recur relatively frequently, are widely used in the speech community, and have achieved a certain level of recognition or acceptance, if not normative approval ${ }^{5}$ (Hasselmo 1969; Mackey 1970; Poplack and Sankoff 1984).

An initial perusal of the Ottawa-Hull corpus reveals a particularly complex situation. Coexisting with words which presumably satisfy the above-mentioned criteria for loanword status (such as chum, fun, gang) are others which are equally integrated from the linguistic point of view (such as coper or firer, as in [1]), but for which the frequency and acceptability criteria are unclear or nonexistent.

(1) a. Je serais pas capable de coper ([ko'pe]) avec. $(037 / 1086)^{6}$ 'I couldn't cope with it.'

b. Il est pas capable de firer ([fai'ке)] ses curés. (068/1116) 'He can't fire his priests.'

Contrary to the traditional characterization of established loanwords, we find unadapted English morphemes conjoined with French verbal and participial affixes, repetitions of the same lexical item which do not always recur in the same phonological form, even when uttered by the same speaker (see also Mougeon et al. 1985b); French affixes may even be rendered in an anglicized way, so that the entire word will have French morphology but English phonology.

The distinction between linguistically integrated momentary or nonce borrowings such as coper and firer and well-established loanwords like tougher and déplugger, as in (2), is not always recoverable from the structural form of the individual word.

(2) a. Ils toughent ([tof]) pas longtemps, on dirait; ils partent. (001/49) 'They don't tough it out too long, it seems; they leave.'

b. Puis les parents ont jamais voulu qu'ils la dépluggent, ([de'plog]) mais elle est morte quand même là. (112/1883)

'And the parents never wanted them to unplug her, but she died anyway.'

Methodological difficulties in distinguishing single borrowed words in context from single code-switched items further complicate the descrip- 
tion of patterns of bilingual behavior. The consequences for a theory of bilingualism of systematically mistaking code-switching for borrowing or vice-versa are even more serious. In order to assess the role of each of the above phenomena in the bilingual repertoire of the community and to ascertain whether established loanwords have different structural properties from nonce borrowings, and whether these in turn may be differentiated from code-switches, we undertook a large-scale, comprehensive study of all SINGLE-ITEM English-origin forms in the corpus, that is, all forms which were operationally excluded from a previous study of the same speakers' code-switches (Poplack 1985), initially defined as MULTI-WORD $\mathrm{L}_{2}$ sentence fragments which remain morphologically and syntactically unadapted to recipient-language patterns, as in the italicized portions in (3).

(3) a. Il a dit que des fois là, quand il marchait là, il marchait over dead bodies. (014/746)

'He said that sometimes when he walked, he was walking over dead bodies.'

b. J'ai la- la philosophie ancienne on va dire, que, tu sais, si tu as faim, get off your ass and go and work, tu sais? (105/212) 'I have the- the old philosophy, let's say, that, you know, if you're hungry, get off your ass and go and work, you know?'

Not all of the single-item forms can be expected to represent established loanwords, nor even nonce borrowings, since single-word code-switches are theoretically possible, ${ }^{7}$ but the quantitative analysis adopted here is expected to yield criteria to help distinguish among the different types of $\mathrm{L}_{2}$ incorporations in $\mathrm{L}_{1}$ discourse.

\subsection{The data base}

From each individual interview we extracted all single words of English origin occurring naturally in an otherwise French context. For this study we adopted the widest possible definition of 'word of English origin', including names which are clearly etymologically English, though they may not have a current French equivalent (tennis, hockey, hamburger), very old and well-established loanwords which may no longer be perceived as borrowed by either dictionaries of canadianismes or the speakers themselves (for example, sandwich, club, steak), and French-English homographs given in English phonology even when not etymologically English (super, spaghetti, ghetto). ${ }^{8}$ This broad view of borrowing allows for maximal variability, hence maximal opportunity to distinguish 
speaker behavior with regard to imported forms. Indeed, we will see that certain sectors of the population are characterized by the use of old, established loanwords which have fully penetrated other varieties of Canadian - and in some cases, European - French, while nonce borrowings are more prevalent among other speakers.

The existence of metalinguistic commentary, reflections on the part of the speaker indicating awareness that the word was English, perceptible hesitations or false starts in the immediate context, and the occurrence of words in reported speech were noted; all items in these environments were subsequently excluded from the data base, retaining only forms used naturally in the context of French discourse.

Nineteen thousand five hundred and seventy-nine tokens of English origin constitute the final data base.

\subsection{Coding procedures}

All occurrences of a given English-origin word were considered tokens of the same lexical type. Each type was coded according to the number of speakers using it as well as the total number of times it occurred in the corpus. Also noted were the grammatical category of the borrowed type (to assess the permeability of different parts of speech to borrowing), ${ }^{9}$ the grammatical gender attributed to each occurrence (in order to measure gender consistency), the meaning of the word when more than one was possible in English (for example, high, 'elegant' vs. high 'drugged'), to determine whether the English form entered as part of a particular expression or whether it is used in many or all of its English senses, and the syntactic context when this differed from normal French or English usage, as in (4), to determine the degree of syntactic integration.

(4) a. Parce que toute s'en vient computer astheure. (037/387)

'Because everything is becoming computerized now'.

b. Quelqu'un m'a dit que j'ai été reincarnation quatre fois. (041/1884)

'Somebody told me that I have been reincarnated four times.'

In addition, all borrowings used by more than ten speakers (a total of 142 types), supplemented by a subsample of those used less frequently and a selection of unambiguous code-switches, were transcribed in narrow phonetic transcription. This enables us to compare intra- and interspeaker variability in the segmental and suprasegmental integration of a borrowed word. We may thus ascertain whether socially integrated (frequently used) borrowings show different structural properties from momentary ones and/or code-switches. 
Some 500 borrowed types, including all those having attained a midfrequency level (that is, those used by six speakers or more), as well as a subsample of those used less frequently were systematically searched in two European French dictionaries (the Petit Robert and the Französisches Etymologisches Wörterbuch) and ten specifically Canadian French prescriptive and descriptive sources dating from 1880 to the present, ${ }^{10}$ to ascertain whether the word is also attested in one, both, or neither of European and Canadian French, its first date of attestation, and the sense(s) in which it is attested. We could then assess whether the borrowed word is also a member of the 'international French' lexicon, is a canadianisme, or is idiosyncratic to the Ottawa-Hull region, to a particular neighborhood, or to a particular speaker.

\subsection{The analysis}

Observing what appeared to be intra- and interspeaker variability in loanword use, we first distinguished frequently used words in the speech of a single speaker (such as barracks, as in [5]), to which we refer as idiosyncratic, from nonce borrowings, such as in (1). ${ }^{11}$

(5) a. Il y avait ... quatre grosses bâtisses de barracks. (041/63)

'There were four large barracks buildings.'

b. Avant ça, la- la guerre, c'était un hôpital avant, puis le barracks pour l'armée. (041/64)

'Before that, the- the war, it was a hospital, and [there were] the army barracks.'

We also distinguished words in widespread use (by more than ten speakers), as in (6), from recurrent ones (said more than ten times, though not necessarily by as many speakers), as in (7). ${ }^{12}$

(6) a. Il dit, 'tu as vingt-quatre ans, je peux pas te kicker dehors'. $(064 / 1519)$

'He says, "You're twenty-four years old, I can't kick you out".'

b. Je voulais pas que ça se perde, la viande, avec la bunch que j'avais à table. (069/829)

'With the bunch I had to feed, I didn't want the meat to spoil.'

c. C'est pareil comme ... parle à un bloke, lui il va dire, 'hey crisse, elle parle bien weird, elle'. (037/1492)

'It's like ... speak [French] to an anglophone, and he'll say, "Christ, she talks weird",'

(7) a. Ils se frappaient ensemble puis tu allais revoler, tu landais dans le canot de l'autre, puis l'autre tombait dans l'eau. (025/2300) 
'They would crash together and you'd go flying, you'd land in the other guy's canoe and he'd fall in the water.'

b. Je la lis steady, ma l'horoscope [sic]. (40/2018)

'I read my horoscope regularly.'

In sections 3-6, our analysis focuses on two complementary aspects of loanword integration. The first approach consists basically of calculating the distribution, over all the borrowed words in our sample, of various indices of integration: social (frequency of use), historical (in terms of attestation history), and linguistic (phonological, morphological, and syntactic), and then cross-tabulating or otherwise comparing different pairs of these indices. For example, we compare the number of speakers using each word with its individual date of attestation in order to investigate the relationship between the length of time the word has been attested and its present frequency of use. Construction of the linguistic measures is detailed in sections 3 and 4 .

The second approach, in sections 5 and 6 , involves the comparison of some of these properties of borrowings with the sociodemographic characteristics of the speakers who use them: age, sex, educational and socioeconomic levels, degree of proficiency in English, and neighborhood of residence.

Though the data we have described allowed us to investigate the relationship between speakers' English proficiency and the use they make of borrowing, and though we could compare the degree of phonological integration of a loanword with its frequency of use, we also undertook to characterize speakers directly in terms of their tendencies to assimilate borrowed words into host-language patterns. This could then be correlated with English proficiency and the other sociodemographic factors (section 4.5).

The comparison of borrowing statistics reveals the differential behavior of speakers in the number and kinds of loanwords they use. It provides no information on the borrowed lexicon itself: to what extent the same words, rare or frequent, are used in various groups, and to what extent each group has its own repertoire. Thus, in section 6 we detect loanword concentrations by constructing lists of words statistically 'associated' with each group. We expand on this by determining quantitatively whether the stock of loanwords is regionally homogeneous or whether different ones are favored in each neighborhood. How does the distribution of commonalities and differences between age groups, neighborhoods, and occupational classes reflect generational, geographic, political, or social divisions and the patterns of communication across them? To shed light on these questions, we also develop in section 6 an index of sharedness or commonality of loanword usage. 


\subsection{Overall distribution of English-origin words}

Despite what is a very large and representative data base for a study of potential loanwords, we note first from Table 1 that these forms represent, on the average, under $1 \%(0.83 \%)$ of the total verbal output. This is evidence of the exceedingly. small role borrowed vocabulary actually plays in the lexicon, even in an actively bilingual region such as Ottawa-Hull. These tokens correspond to 2183 types (or different words), which in turn represent an average of $3.3 \%$ of the total vocabulary. ${ }^{13}$

We noted above that borrowed words tend not to be recurrent (see also Mackey 1970; Poplack and Sankoff 1984; Mougeon et al. 1985b): for content words to recur, speakers must be talking about the same thing and be able to access the same English-origin word denoting it, while function words, though frequent, are only rarely borrowed. The OttawaHull corpus, though appreciably larger than other data bases, is no exception. Fully $65 \%$ of the different borrowed types were uttered by only one speaker, no more than $12 \%$ were used by two speakers, $5 \%$ by three speakers, and so on. The proportion of English-origin words which can be considered to be truly widespread in the community ${ }^{14}$ is only $7 \%$.

Despite the fact that the 142 widespread loans make up such a small proportion of all the borrowed types, by definition they are each used by many speakers (about 30 on the average), so that the typical speaker actually uses more different widespread types than she does of the 2000

Table 1. Average distribution of loanwords per person $(N=120)$

\begin{tabular}{|c|c|c|c|c|}
\hline & $\begin{array}{l}\text { N: } \\
\text { Mean }\end{array}$ & $\begin{array}{l}\text { Standard } \\
\text { deviation }\end{array}$ & $\begin{array}{l}\%: \\
\text { Mean }\end{array}$ & $\begin{array}{l}\text { Standard } \\
\text { deviation }\end{array}$ \\
\hline Borrowed tokens & 163 & 115 & $\begin{array}{l}0.8(\% \text { of all } \\
\text { tokens) }\end{array}$ & 0.5 \\
\hline Borrowed types & 69 & 43 & 3.3 (\% of all types) & 1.9 \\
\hline $\begin{array}{l}\text { Idiosyncratic types (used } \\
\text { by one speaker) }\end{array}$ & 11 & 15 & $\begin{array}{l}13 \text { (\% of borrowed } \\
\text { types) }\end{array}$ & $8.1^{\circ}$ \\
\hline $\begin{array}{l}\text { Nonce borrowings } \\
\text { (occurred once in } \\
\text { corpus) }\end{array}$ & 8 & 11 & $\begin{array}{l}10 \text { (\% of borrowed } \\
\text { types) }\end{array}$ & 6.9 \\
\hline $\begin{array}{l}\text { Widespread loan types } \\
\text { (used by more than } 10 \\
\text { speakers) }\end{array}$ & 36 & 16 & $\begin{array}{l}57 \text { (\% of borrowed } \\
\text { types) }\end{array}$ & 12 \\
\hline $\begin{array}{l}\text { Recurrent loan types } \\
\text { (occurred more than } 10 \\
\text { times in corpus) }\end{array}$ & 42 & 20 & $\begin{array}{l}66(\% \text { of borrowed } \\
\text { types) }\end{array}$ & 12 \\
\hline
\end{tabular}

Note: By definition, nonce borrowings are idiosyncratic, widespread loans are recurrent. 
possible nonwidespread types. Conversely, though there are some 1000 nonce borrowings in the corpus, accounting for about $50 \%$ of all the borrowed types, these are distributed at one occurrence each, throughout the sample, so that they constitute only about $10 \%$ of the average speaker's repertoire of borrowed types (Table 1). The Ottawa-Hull francophone, then, tends to use her loanwords recurrently, favoring those which are also in use by a number of other speakers. Only rarely does she resort to nonce or idiosyncratic borrowings.

We show in section 5 how this composite pattern varies, according to individual factors of age, sex, educational attainment, socioeconomic status, neighborhood of residence, and English-language proficiency. We turn first to the linguistic properties of these borrowed words.

\subsection{Lexical integration of borrowed forms}

The stock of frequently used loanwords in Ottawa-Hull may be largely characterized as forming part of the wider Canadian French and, to a lesser extent, the International French lexicon (Table 2). A large majority $(78 \%)$ of the words in widespread use in the region are attested in one or more of the Canadian French sources consulted, while more than half are also cited in European French sources. Though understandably enough, fewer words used by the Ottawa-Hull speakers appear in European than in Canadian sources, it is noteworthy that so many of them are actually 'international' loanwords. The percentage of attestations in either Canadian or European sources drops in a regular and parallel fashion as does

Table 2. Attestations of loanwords in European (EF) and Canadian French ( $C F$ ) sources by frequency of usage categories

\begin{tabular}{lllll}
\hline $\begin{array}{l}\text { Number of } \\
\text { speakers using } \\
\text { word }\end{array}$ & $\begin{array}{l}\text { Words } \\
\text { attested in EF } \\
\text { sources (\%) }\end{array}$ & $\begin{array}{l}\text { Words } \\
\text { attested in CF } \\
\text { sources (\%) }\end{array}$ & $\begin{array}{l}\text { Words not } \\
\text { attested (\%) }\end{array}$ & Total \\
\hline $\begin{array}{l}\text { Over } 10 \\
6-10\end{array}$ & 53 & 78 & $18^{\mathrm{a}}$ & 144 \\
3 & 38 & 75 & 22 & $144^{\mathrm{b}}$ \\
1 & 30 & 62 & 36 & $100^{\mathrm{b}}$ \\
Total & 12 & 18 & 80 & $96^{\mathrm{b}}$ \\
\hline
\end{tabular}

\footnotetext{
"Percentages will not add up to 100 because most words attested in European French are also attested in Canadian French.

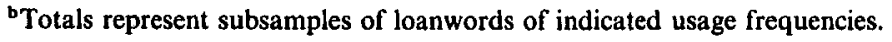


the number of speakers using the word, such that only $18 \%$ of the words used by a single speaker can be found in a Canadian dictionary (such as pinch 'goatee', reel, tag, trimpe 'tramp'), and even fewer $(12 \%)$ in a European French source (such as afro, kidnapper [v], revolver, scooter). That $80 \%$ of the nonce and idiosyncratic borrowings are not found in any source, while an equal proportion of those used by over ten speakers is attested in one or more sources, is a key feature distinguishing the established loanword from the nonce borrowing. Moreover, Figure 2 shows that among the borrowed words appearing in the Ottawa-Hull corpus, it is precisely the earliest attested which were most likely to be recurrent and widespread in 1981, when the data were collected (such as bill, boss, check [n], fun, gang, kicker [v], lunch, rough, shed, toast). More than a quarter of the words used by more than ten speakers had already been attested by 1880; the proportion rises to half for attestations by 1900 , and more than three-quarters appear in the sources by 1970 . In contrast, only $4 \%$ of the words used by a single speaker had been attested in 1880 ; indeed, no more than $18 \%$ had entered the dictionaries as recently as the mid-1970s. The fact that very few of the words which we had operationally classified as 'nonce' have ever been attested is confirmation of the quantitative validity of this classification.

Thus the most frequently used borrowings in the Ottawa-Hull region represent what may be termed accepted loanwords: those attested in dictionary lists as part of the lexical stock of the (Canadian or European) French language.

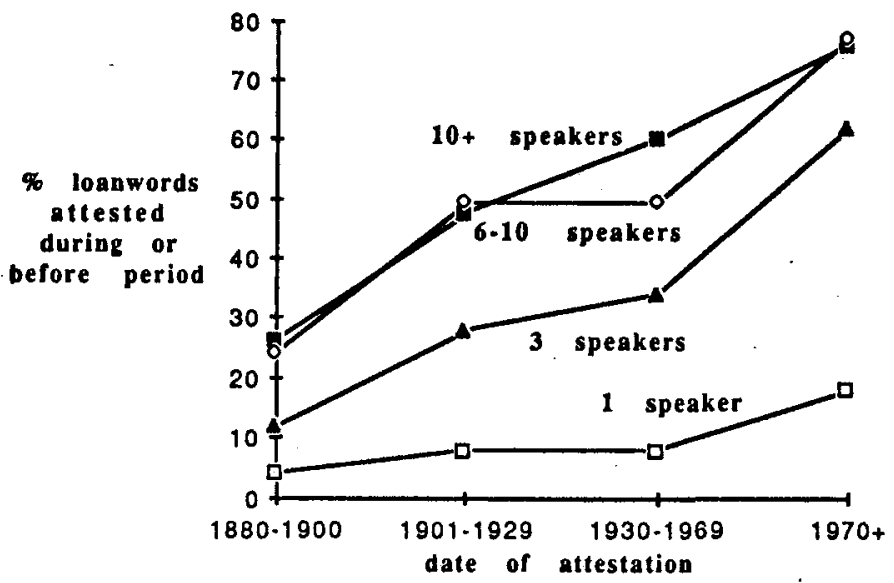

Figure 2. Cumulative rates of previous attestation of loanwords according to number of speakers using them in the Ottawa-Hull corpus 


\subsection{Semantic distribution of borrowed words}

Various proposals have been advanced in the literature regarding motivations for lexical borrowing. Weinreich (1968) cites factors of a psychological nature as well as the notion of lexical need (see also Haugen 1969) on the part of the recipient-language speakers.

Thus, the use of snap for bouton-pression or truster for se fier $a$ in Ottawa-Hull French might be explained by a psychological preference on the part of speakers for morphologically simple lexical items over more complex ones to express the same referent. Similarly, the borrowing of cute for mignon is conceivably motivated by a desire for synonyms to distinguish registers. Data from actual loanword usage, however, can only be brought to bear on such psychological motivations in a peripheral and post-hoc fashion.

Our materials may be somewhat more pertinent to the question of lexical 'need' as a motivating factor in borrowing. Indeed, numerous borrowings designate referents associated with a North American or specifically Canadian context (see [8]). It should not be surprising that gaps in $L_{1}$ vocabulary created by the introduction of new referents via the English-speaking world are often filled by lexical items from English.

To assess the extent to which lexical 'need' could account for the use of borrowed vocabulary in the region, we grouped the approximately 2000 borrowed types in our corpus into rough semantic fields, such as nationality, language, means of transport, school and studies, animals, and television, among others. ${ }^{15} \mathrm{We}$ were able to classify the majority of words, but only through use of a large number of categories (50) and rather weak criteria for inclusion therein.

(8) Semantic fields containing concentrations of loanwords possibly attributable to need:

a. Automobiles and related vocabulary:

bumper, muffler, rim, running board, spoke, steering [wheel], tire, flat, gaz

b. Drugs:

dime [of hashish], joint, hash, grass, pot, speed, stuff, trip

c. Food:

bacon, barbecue, cheeseburger, ginger-ale, hot-dog, hamburger, ketchup, muffin, sandwich, toast, popsicle, club [sandwich]

d. Clothes and fashion:

afro, shaggy-dog, bikini, jeans, t-shirt, shorts, punk 
e. Music and dance:

blues, country, jitterbug, jive, new-wave, punk-rock, reel, rock, set, slow, western

f. Games:

bingo, mini-golf, ping pong, pinball, alleys 'marbles', balloon, hula hoop, kick-can, yoyo, tag

g. Sports:

bowlathon, softball, badminton, baseball, basketball, football, hockey, jogging, pad, volleyball, aréna, bantam, midget, pee-wee

h. Computers:

output, input, feedback, computer

i. Politics, law, crime:

coronation, bill, lobbying, jury, screw 'prison guard', stooler (v) 'to be a stool pigeon'

j. Logging terms:

drave 'lumber drive', slab 'firewood', skidway, skidder (v)

Note that many of the borrowings apparently motivated by need are concentrated in certain semantic fields. These are indeed areas where influence from the ambient anglophone culture and institutions is palpable. Nevertheless, the number of borrowings that can be ascribed to lexical need in Canadian French is negligible in comparison with those for which such motivation is absent. Categories containing any significant numbers of such items are by far outnumbered by those where any 'need' for a new word would be difficult to confirm, and even in the small minority of semantic fields with any appreciable number of needmotivated borrowings, these only represent a very small proportion of the total. In fact, as exemplified in (9), for most of the widespread loans in our corpus, lexical need cannot be hypothesized to play a significant role. The most important factors accounting for the inventory of borrowed words are the historical and geographical transmission from other varieties of European and Canadian French, in addition to the local situation of massive contact with the socially dominant English language.

(9) Examples of widespread loans for which lexical need plays little or no role:

$\begin{array}{ll}\text { appointment 'meeting' } & \text { first } \\ \text { business } & \text { smart } \\ \text { runner (v) 'function', 'drive' } & \text { watcher (v) } \\ \text { feeler (v) } & \text { bad luck } \\ \text { gang 'bunch' } & \text { anyway } \\ \text { rough } & \text { steady (adv) }\end{array}$




$\begin{array}{ll}\text { friendly } & \text { wrong } \\ \text { no way } & \text { fun } \\ \text { okay } & \text { checker (v) } \\ \text { chum } & \text { game } \\ \text { building } & \text { party }\end{array}$

\subsection{Linguistic integration of loanwords}

In order for borrowed material to be fully integrated into the recipient language it must be adapted into the existing patterns of that language. Words borrowed into French must first be assigned to a grammatical category; nouns (and eligible adjectives) must be assigned a gender, and if plural, inflected for number. Verbs must be inflected for tense, mood, and person. In addition, the phonological shape of the borrowed item may be made to conform with recipient-language patterns. Much vacillation has been noted in the process of linguistic integration of loanwords, at least in the areas examined in the literature: that is, their assignment to a gender (Haugen 1969; Arndt 1970; Baetens Beardsmore 1971) and their phonological integration (Haugen 1950; Mougeon et al. 1985a). This has generally been given a psycholinguistic explanation: the more bilingual speakers, in an effort to faithfully reproduce source-language material, may deviate from the patterns of the remainder of the community (Haugen 1950; Mougeon et al. 1985a). In what follows we investigate whether those inconsistencies in linguistic integration which do exist at the community level are a function of the degree of (social) integration of a loanword, that is, its level of diffusion throughout the community.

\subsection{Borrowability of different parts of speech}

We first examine which grammatical categories are most receptive to borrowed material. It has been hypothesized (for example, Weinreich 1968: 35 ) that the more highly bound the morpheme (such as inflections, case endings, function words), the less likely it will be to undergo borrowing. Hierarchies of 'borrowability' (see Whitney 1881; Haugen 1950; Muysken 1980) suggest that common nouns are by far the most frequently borrowed elements, followed by other grammatical categories with lexical content, morphological elements, and syntactic rules, in that order. Such hierarchies, sometimes based on the proportion each part of speech represents in a corpus of loanwords, may simply reflect the distribution of particular grammatical categories in native-language 
materials rather than their specific propensity to be borrowed. If, however, the proportions of form classes among the borrowed vocabulary were compared with these proportions in the monolingual vocabulary, we would have a more valid indication of the tendencies of each category to accept other-language material.

A survey of the English-origin material in the Ottawa-Hull corpus shows, in accord with previous studies, that the overwhelming majority (64\%) falls into the category of nouns, followed by verbs $(14 \%)$, interjections and frozen expressions $(12 \%)$, adjectives $(8 \%)$, and conjunctions $(1.5 \%)$. No other category reaches $1 \%$ of the data, and most contain none at all (Figure 3).

We next compare this with the distribution of parts of speech in the monolingual French corpus. While we obviously could not parse all the monolingual material, given the excessive size of the corpus from which the borrowed words are extracted, we estimated, from some 19,000 words of running text, ${ }^{16}$ the proportion of monolingual French forms in each of the grammatical categories. Figure 3 compares the proportions of native to borrowed forms in each part of speech.

If borrowing into the various grammatical categories mirrored monolingual tendencies, we would expect to find comparable proportions of native and borrowed forms in each part of speech. However, the predilection for borrowing nouns exceeds by more than a factor of five the frequency of this category in French.

Even when nouns are combined with pronouns (most of which may be argued to refer to the same extralinguistic reality, and which represent the most frequently occurring category in French, ${ }^{17}$ though they are virtually

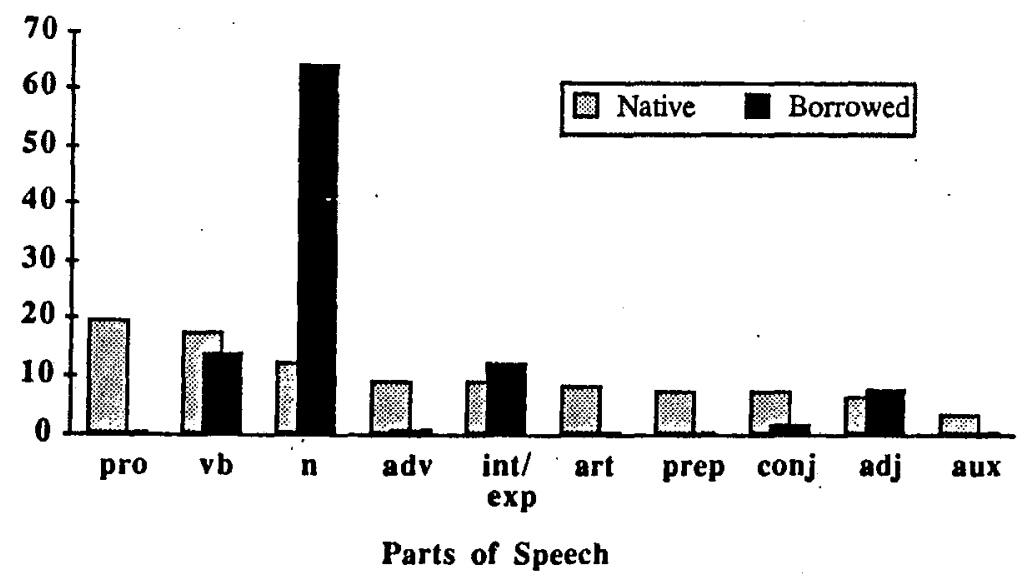

Figure 3. Percentage of each part of speech in native and borrowed lexicon 
nonexistent in the borrowed materials), we still find that the proportion nouns make up of all borrowed types is more than twice that of the two categories combined in monolingual discourse.

Thus we may confirm that nouns have a particular propensity to be borrowed, over and above their frequency of occurrence in the host language. Indeed, for all practical purposes, transfer from English into French affects only three other grammatical categories: verbs, adjectives and interjections/frozen expressions. ${ }^{18}$ The latter two are also somewhat overrepresented, compared with what their frequency in monolingual speech would warrant, though not nearly to the same extent as nouns. The next most frequently borrowed category, conjunctions, represents only $1.5 \%$ of the data. Even this figure is due to the high frequency ( 397 - occurrences uttered by over a third of the informants) of so, an integrated loanword in Ottawa-Hull (and other varieties of Canadian French; see Roy 1981; Mougeon et al. 1985c). Though each of because, but, except, and or also occurred, these remain at the level of nonce or idiosyncratic borrowings. All other parts of speech are either nonexistent (presentational and demonstrative pronouns, articles, prepositions) in the borrowed lexicon or are exceedingly rare: personal pronouns (itself, theirself, whatever, whoever - all nonce or idiosyncratic), and somewhat surprisingly, given their relative structural freedom, adverbs (for example, bum, first, back, as in [10]).

(10) a. Je me vois pas tellement en train de parler pas mal bum. (097/2457)

'I just don't see myself talking really carelessly.'

b. Les anglais, ils usent leur langue first, pourquoi c'est qu'on le ferait pas nous autres? (045/1688)

'The English use their language first, why shouldn't we?'

c. Puis je lui ai ramené le cinq cennes back. (065/1999)

'And I gave him back the nickel.'

Borrowing from English into French is not only largely concentrated in four grammatical categories, but it is basically only these which figure among the stock of loanwords in widespread use in the region. ${ }^{19}$ Only three adverbs (back [18 speakers], first [11], and steady 'regularly' [30]); two interjections (so [discourse marker] [12], sure [19]), and the conjunction so (42) are used by more than ten speakers. Even in the midfrequency range (6 to 10 speakers), only two interjections $h i$ (7), my god (10) and one adverb (slow 'slowly' [6]) are recurrent.

It has been suggested (Weinreich 1968:36) that if one could measure the frequency of different forms in the lexicons of various members of a speech community it might be possible to prove whether the reception of 
transferred forms is subject to a selective resistance inherent in the recipient grammar; that is, whether certain forms are accepted more readily by the highly bilingual speakers - the agents of importation than by the remaining monolingual members of the group. An initial examination of the distribution of all borrowed words across grammatical categories shows virtually no differentiation for any sector of the population from the figures already presented. This result, however, masks the fact that nonce and other rare borrowings pattern in a different way from more widespread loans. We will see later that certain individuals, the most innovative speakers in the sample (section 5 below), use the largest number of nonce borrowings, which are, to a greater extent than other loans, nouns. On the other hand, when we examine the lexical stock ASSOCIATED with different subgroups of speakers (that is, those relatively high-frequency words for which a disproportionate number of occurrences is confined to a particular age, sex, or other subgroup), we will find that increased proportions of loanwords of grammatical categories other than nouns - the unmarked category - are typical of these same innovative individuals. The other speakers have the same overall proportion of nouns, but this is because they compensate for fewer nonce words by more nominal use among their widespread loans. Thus, one of the concomitants of innovative borrowing is the ability and propensity to borrow into grammatical categories other than nouns, where both morphological and syntactic adaptation must be made. We examine these adaptations in the following sections.

The explanation of why borrowing should be largely restricted to nouns in particular, and the other five parts of speech more generally, surely resides in a combination of the facts that (1) they are structurally less integrated into the recipient discourse, thus facilitating transfer, and (2) they are the forms with most lexical content (Whitney 1881; Tesnière 1939; Haugen 1950; Weinreich 1968; Lefebvre 1984; Muysken 1984).

\subsection{Consistency of gender assignment to borrowed nouns}

An earlier cross-linguistic study of the factors determining assignment of masculine or feminine gender to borrowed nouns in Montreal French and Puerto Rican Spanish (Poplack et al. 1982) showed how these are language-specific, that is, they follow from the rules for gender assignment to monolingual lexical material. Since the phonological shape of a native Spanish noun accounts for virtually all gender assignments in that language, it was not surprising to find that the same constraints were also operative with borrowed material. In French, on the other hand, where 
gender assignment is only minimally determined by phonological shape, other factors, such as analogical gender and suffixal analogy, are more important predictors of the choice of gender in borrowed words. The relative lack of interspeaker variation in that study led us to emphasize the crucial role of the speech community in the near-unanimous agreement on gender usage, once a gender is assigned to a borrowing. We hypothesized that once a loanword reached a certain level of frequency it would be transmitted, along with a fixed gender, to all segments of the society in much the same way as monolingual neologisms.

The present analysis, based on some 550 borrowed types showing unequivocal indications of feminine or masculine gender for at least one token, ${ }^{20}$ basically confirms that claim and shows that consistency of gender assignment to loanwords is achieved even earlier in the assimilation process than previously thought.

. Figure 4 graphs three measures of consistency in assignment of grammatical gender to words of varying frequencies of usage. The first focuses on those words showing variable gender assignment, measuring how many have non-negligible proportions of both genders, and how many receive one gender overwhelmingly. From the line labeled 'variable' in Figure 4, it can be seen, for those words assigned both genders at least once in the corpus, that the predominance of a single gender (as measured by the average, in each frequency class, of the proportion of the majority gender for each noun) increases with frequency of usage. This suggests that gender consistency is increasing with usage frequency. On the other hand, we may wish to count as consistent only those words marked $100 \%$

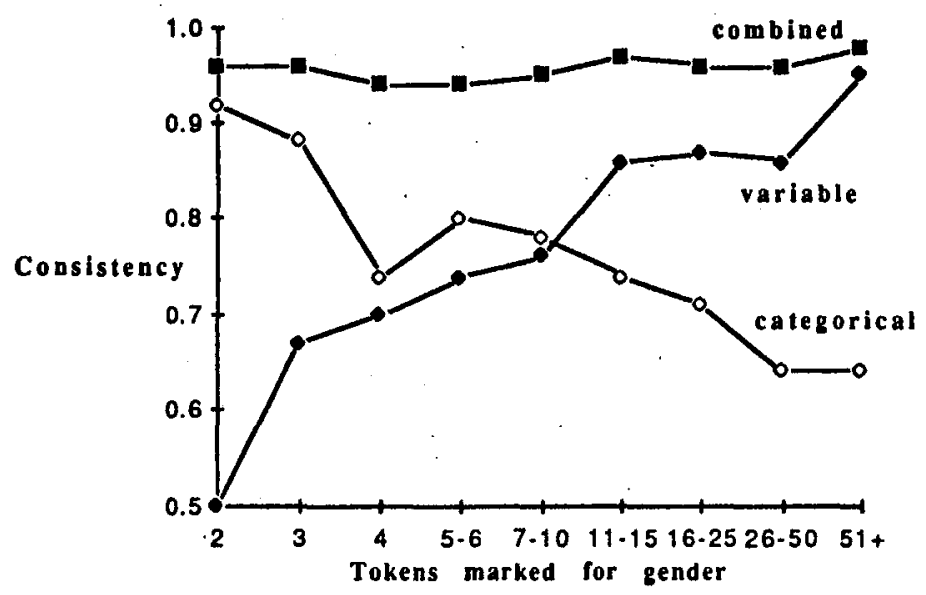

Figure 4. Gender consistency as a function of loanword frequency 
of the time with the same gender. The figure shows that the proportion of nouns showing CATEGORICAL gender assignment actually decreases as usage frequency increases.

The apparent paradox involving the two measures of consistency, one showing increasing, and the other decreasing, consistency as a function of frequency, can be resolved through the hypothesis that all nouns are assigned a fixed gender, but that each occurrence is susceptible to a small, but constant, error rate (around $4 \%$ ). When this error affects a lowfrequency type with, say, two occurrences, this leads to an apparent assignment of $50 \%$ feminine, $50 \%$ masculine gender, whereas for words of high frequency the error will lead to about $96 \%$ attribution of one gender and $4 \%$ the other. Indeed, out of 90 words in the corpus with more than ten tokens marked for gender, only six showed more than $10 \%$ gender variation: traite 'treat' $(87 \% \mathrm{~F})$, business $(85 \% \mathrm{~F})$, football $(79 \% \mathrm{M})$, bar $(75 \% \mathrm{M})$, building $(60 \% \mathrm{M})$ and baseball $(58 \% \mathrm{M})$. This prediction explains the curve of rising consistency with frequency among words showing variable gender. On the other hand, a type with only two tokens will hardly ever be affected by a $4 \%$ error rate (only once for every 12 or 13 such types), explaining why consistency in terms of categorical gender declines with frequency. If we use an overall measure of consistency, such as the proportion of tokens of each type which evidences the majority gender (the curve labeled 'combined'), this is found to stay remarkably constant across the entire range of frequencies. Note that this rate of consistency holds equally well for the $27 \%$ of loanwords assigned feminine gender as for the masculine ones.

That gender assignment to loanwords is not categorical may well reflect the fact that gender variability in monolingual French words is also attested in this corpus, though we have not yet ascertained whether this reaches the level of a $4 \%$ error rate. Nevertheless, the important result here is that gender assignment appears to be made very consistently (96\%) starting quite early, that is; as soon as minimal frequency of use can be detected (in our corpus, with the appearance of at least two gendermarked tokens).

\subsection{Morphological integration of loanwords}

4.3.1. Plural inflection in borrowed nouns. When a speaker uses an English noun with a plural referent in French discourse he must decide whether to follow English rules (in affixing a [z] to the noun) or French rules ([ø] affix) for plural marking. The overwhelming majority of plural nouns in the corpus, excluding the lexicalized plurals jeans, shorts, comics 
'cartoons', mumps, ${ }^{21}$ follow French rules for plural marking: that is, they show [ø] affixation. Nonetheless, as in the case of gender assignment, there is some variability here as well. Examination of rates of French plural marking in words of varying usage frequencies shows that tendency to receive French affixation increases as a function of the diffusion of the word (Figure 5), albeit marginally: from $85 \%$ of plural words used by a single speaker to $98.4 \%$ of words used by more than ten speakers. Thus, here again, French plural inflection, when required, is the norm, even for nonce borrowings, and becomes virtually categorical for more frequently used words.

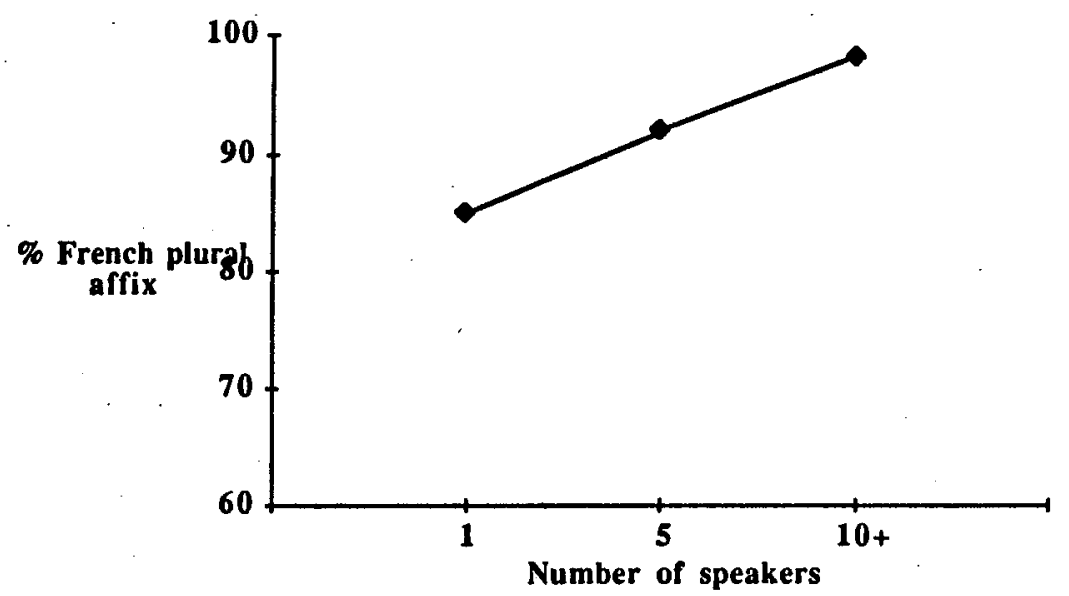

Figure 5. Rate of French plural affixation by frequency of usage

4.3.2. Verbal morphology. Unlike the case in many languages (for example Kachru 1978 for Hindi; Sankoff et al. 1986 for Tamil; Romaine 1985 for Panjabi; Madaki 1983 for Hausa; Smith-Stark 1976 and Norman 1976 for Mayan), where verbs are borrowed as untensed bare infinitives and accompanied by a preposed or postposed native pro-verb carrying all tense, mood, and aspect marking, the English bare infinitive itself serves as the root for conjugation when borrowed into French. All verbs in the corpus are placed in the first conjugation (the -er class) and conjugated according to French patterns (wherever these differ from English in showing an overt mark). Widespread verbs include afforder, brainwasher, checker '(1) check out, (2) undergo a medical examination, (3) hockey term', délivrer, déplugger 'unplug', figurer 'conclude', feeler, mover '(1) change residence, (2) change place of', runner '(1) direct, (2) drive (vehicle), (3) function (machinery)', shopper, skipper '(1) cut class, (2) skip 
a grade, (3) skip rope', tougher 'to tough it out', user 'to utilize', watcher.

4.3.3. Other parts of speech. French adjectives agree with their head noun in number and gender; the former is expressed by the [ø] suffix, while the latter is indicated on eligible adjectives by a variety of morphological means. Whereas nouns occasionally, though rarely, were inflected with the English plural affix, the English-origin adjectives in the corpus show categorical [ø] affixation whether plural or singular. None is inflected for gender. (Participial adjectives, such as addicté, crampé, dopé, fücké, shiné 'spiffy', are of course ambiguous in this regard since number and gender markers are orthographic only). Derivational morphology is exceedingly rare (for example, toughable 'able to be toughed out' trustable 'trustworthy').

French adverbs formed from most adjectives take the -ment 'ly' suffix. The few English-origin adverbs in the corpus tend to show neither French nor English affixation, as in (11).

(11) a. Ils vont dire, 'parle slow, m'as comprendre'. (066/1852) 'They'll say, "talk slowly and I'll understand".'

b. Et pis elle pliait sa couche, pis là elle l'attachait, pas trop tight, hein? (87/1011)

'She'd fold his diaper, and she'd fasten it, not too tightly, eh?'

\subsection{Syntactic integration of loanwords}

Integration of loanwords into host-language syntactic structures is virtually categorical. Of the approximately 20,000 borrowed tokens in the corpus, only $10(0.05 \%)$ were used in a manner that clearly diverged from French syntax. Most of these involved omission of an obligatory definite article, ${ }^{22}$ as in (12).

(12) a. Ils ont passé par la vitre arrière du char, pour voler le stéréo, et puis ø speakers, des affaires comme ça. (061/777)

'They climbed through the back window of the car, to steal the stereo, and speakers, all that stuff.'

b. Là pour le moment ça va être $ø$ word processing, là je fais des études de psychologie le soir. (061/81)

'So for the moment it's going to be word processing, and I'm studying psychology at night.' 
Though this is not directly pertinent to loanword integration, it is of interest that almost all the borrowed tokens were assigned to the grammatical category corresponding to their English source. Only eight $(0.05 \%)$ exceptions were found, largely nouns used in an adjectival sense, as in (13) and (4) above.

(13) Tu sais, parce qu'ils étaient pride, ce monde-là. (007/538)

'You know, because they were proud, those people.'

Not only are syntactic anomalies exceedingly rare, but they are restricted to the Ottawa neighborhoods and to a few individuals within them, half having been uttered by three speakers. Not surprisingly, individuals who deviate from French syntactic patterns turn out to be highly proficient in English, while those using forms which do not correspond to English grammatical categories are less so.

\subsection{Phonological integration of loanwords}

In addition to its functioning as a syntactic unit of the recipient language (that is, through assignment to a grammatical category and a gender, when applicable, inflection for number and person, and insertion in an appropriate syntactic slot), one may also expect the phonological shape of the borrowed word to conform to native patterns, at least insofar as established (that is, widespread) loanwords are concerned. This of course is precisely what we observe in such loanwords in English (for example, sauerkraut, calico, toboggan, algebra), where any variability in phonological rendition is language-internal and does not alternate between donorand recipient-language patterns. Such is also the case for a number of old (attested before 1930) and widespread loanwords from English in OttawaHull French, which are invariably realized with French phonology (for example, bill, club, grocery, kicker [v], shop, shed, smart, strap, bad luck, loose, record, show, track), as well as for a certain number of more recently attested or unattested words (for example, gimmick, plug, shopper [v], phoner [v]).

Nonetheless, it has been widely observed that the realization of most borrowings shows some degree of phonological variability. Linguists have traditionally ascribed this variability to the age of the loanword, under the assumption that early loanwords show the fullest phonological adaptation to recipient-language phonology, while the more recent ones remain more similar to their models. Haugen $(1950,1969)$. has added the proviso that degree of phonological integration depends not so much on time depth as on the borrower's bilingual ability. He distinguishes among three 
stages of bilingual acquisition (1950:216) ranging from a prebilingual period in which borrowed words show (almost) complete but irregular substitution of native for foreign phones, to one of childhood bilingualism, where donor-language phones are systematically reintroduced. Since the three stages may coexist in a given speech community, it follows that several different renditions of a single loanword may also coexist, what Mougeon et al. (1985a) have recently referred to as 'loanword disintegration'. Indeed, in their study of phonological integration of four loanwords in Ontarian French, they provide evidence that the phonological rendition of one of them (hockey) is correlated with level of bilingual ability, leading them to claim that loanwords can display variable integration depending on the speaker's proficiency in both languages, and that these may undergo phonological disintegration in a community as its members become increasingly bilingual (1985a: 20). They interpret their result as being at variance with earlier findings (Poplack and Sankoff 1984) that phonological integration increases with frequency of use of English borrowings in Puerto Rican Spanish, and that speakers of differing abilities in English do not display much differentiation in levels of integration (1984: 130). Since the 'loanwords' studied by Mougeon et al. (the place names North Bay and. Welland, the nouns hockey and [industrial] plant) were not necessarily the most widespread in the community (1985a: 18), and since the data for two of these words were exceedingly sparse, only their findings for the loanword hockey bear directly on their claim. ${ }^{23}$

Informal perusal of the Ottawa-Hull corpus also shows some variability in loanword phonology, even in words uttered by the same speaker. In this section we systematically examine the relationship between phonological integration, age of attestation, loanword frequency, and bilingual ability.

To determine the extent to which phonological integration is a function of the social integration of a borrowing, we transcribed in fine phonetic detail all tokens of loan types used spontaneously by more than 10 speakers $(\mathrm{N}=142)$, including up to three renditions by a single speaker when available. In addition, from the 2000 types constituting our corpus of borrowings, we selected a subsample of 198 used by fewer than five speakers, including 99 nonce borrowings. Finally, for purposes of comparison, we transcribed a series of content words $(\mathrm{N}=378)$ occurring within substantial stretches of monolingual English discourse: that is, unambiguous code-switches.

Though these transcriptions are impressionistic, it was nonetheless virtually always possible to distinguish English from French realizations. Examples of the former include the importation of phones (such as 
$[\theta, \gamma, \mathfrak{f}, \mathrm{j}]$ and secondary articulations of phonemes (such as velarized [t], aspirated stops, vowel centralization, and reduction to schwa), as well as English stress placement on polysyllabic words. Similarly, variants counted as French include non-English realizations like velar and apical $[R, r]$ and secondary articulations like dental assibilation, vowel diphthongization and syncope, and final stress placement. A third category, ambiguous as to French or English membership, includes articulations that could correspond to either language. For example, since [æ] is a variant of Canadian French /a/, this realization in a word like camper was coded as BOTH English and French. Similarly, [oU] being a variant of Canadian French $/ \mathrm{o} /$, its occurrence in low-rental was considered native to both languages. ${ }^{24}$ For each word studied, then, we obtained between one and 133 transcriptions, all aligned segment to segment (including suprasegmental indications), with spaces left for insertions and deletions, to assure comparison of corresponding segments. We could then calculate an index of integration into French and English, first for each token, then for each type (as a sum of the scores for each token), taking into account inter- and intraspeaker variability. ${ }^{25}$

The index was based on the segments in each type that could have contrasting English and French articulations. For each token, the degree of integration into French was calculated as the proportion of these segments that received French articulation (and conversely for the degree of integration into English). There are at least two possible approaches to handling those articulations which could be considered both French and English. One is to omit the pertinent segment in calculating the index for a token in which such an articulation is detected. The other is to count it positively in both the French and English indices. We report the results from both types of calculation.

We noted above that certain words are always realized in French; others are categorically English (such as proud, check, tank). The majority, however, show some variability, which we can, to some extent, ascribe to extralinguistic factors. Figure 6 displays the overall index of integration into French and English of words uttered by varying numbers of speakers, once counting only unambiguous indicators of the respective phonologies (the solid line), and again including indicators that could belong to either language (the broken line).

The results provide striking confirmation of the observation in Poplack and Sankoff (1984) that phonological integration proceeds as a function of the social integration of the loanword. The figure shows that nonce borrowings are about as likely to be rendered in English as in French, with only a slight bias in favor of the former. Compare this with codeswitches into English, which receive English phonology three-quarters of 


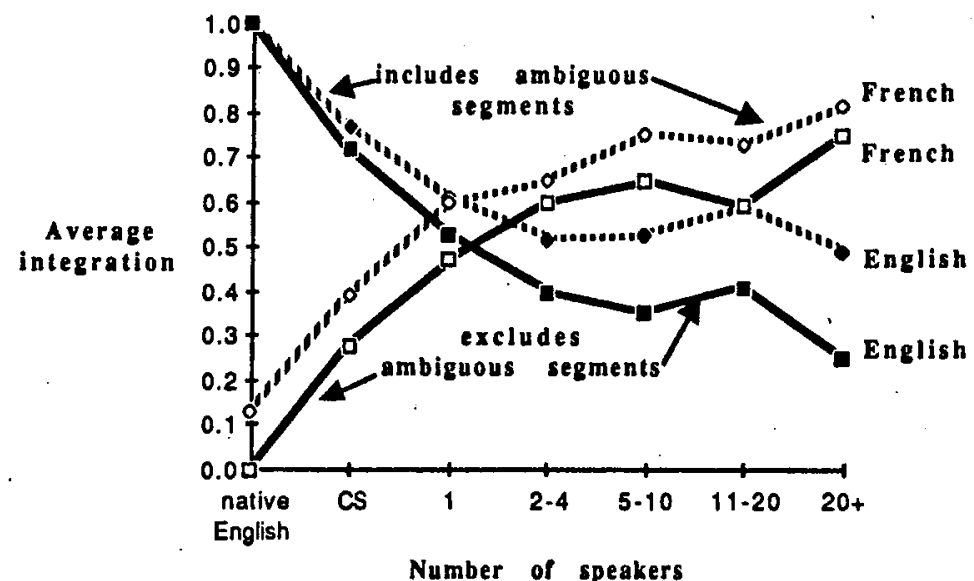

Figure 6. Average integration into French and English of loanwords used by varying numbers of speakers, compared with code-switches and native usage

the time. As we move to the most widespread words, the index of integration rises steadily, so that the likelihood of words used by over 20 speakers receiving French phonology is very high, and English phonology correspondingly low. The same analysis including the results of the ambiguous indicators (including 13\% of the indicator segments in native English words) boosts both the French AND English scores and blurs the effects of frequency somewhat, but is otherwise remarkably similar.

In Figure 7 we assess the effect of date of attestation on phonological integration. This is strikingly parallel - and almost identical in magnitude - to the effect of social integration. Previously unattested words are about as likely to be integrated into French as not, while the oldest words show a strong tendency to assimilate into French phonological patterns. We can thus confirm on the basis of empirical observation the effect of age of the word on loanword phonology (see Trager 1944). We have also demonstrated, despite pervasive variability, the differential treatment of code-switches and borrowings, insofar as phonological integration is concerned.

What of bilingual ability? As part of the same analysis, we were also able to determine each speaker's individual propensity to integrate English-origin words into French phonology. Discounting performance on words which are categorically (or almost categorically) French or English across the whole sample, we calculated individual integration scores from the realizations of the remaining loanwords used. Speakers could be divided into three groups showing low, medium, and high 


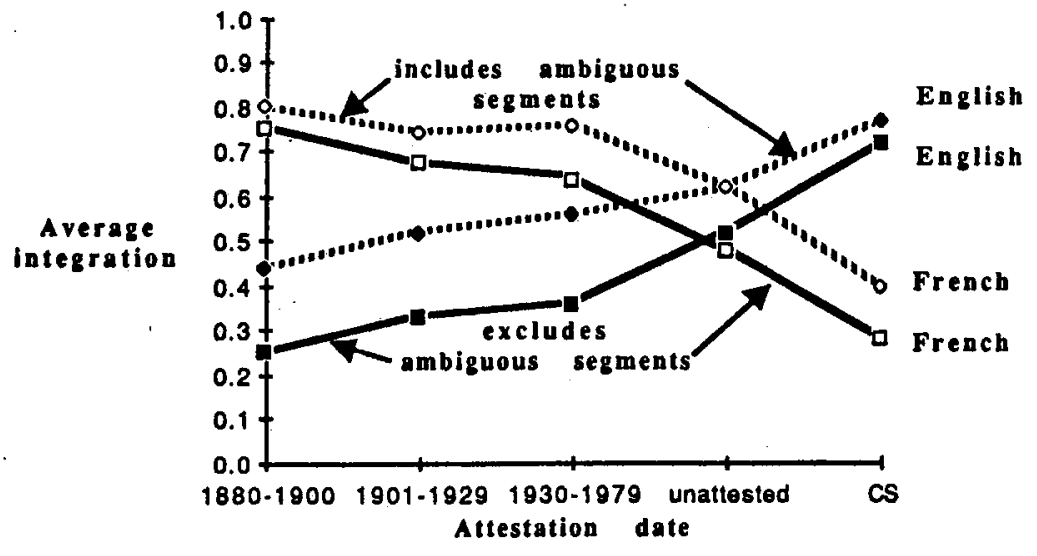

Figure 7. Average integration into French and English of loanwords of varying dates of attestation compared with unattested borrowings and code-switches

tendencies toward phonological integration. There is a close correlation between both English proficiency and neighborhood of residence on the one hand, and propensity to integrate loanwords on the other, as shown in Tables 3 and 4.

Over half the speakers with low proficiency in English show strong tendencies to assimilate borrowings into French phonology, presumably because they have little choice in the matter, while only $14 \%$ of the proficient English speakers tend to do so. Membership in the speech

Table 3. Tendency toward phonological integration by proficiency in English ${ }^{26}$

\begin{tabular}{lllll}
\hline Proficiency in English & \multicolumn{2}{l}{ Tendency to integrate: } \\
& Low (\%) & $\begin{array}{c}\text { Medium (\%) } \\
\text { Low }\end{array}$ & High (\%) & N \\
\hline High & 17 & 32 & 51 & 71 \\
\hline
\end{tabular}

Table 4. Tendency toward phonological integration by neighborhood of residence

\begin{tabular}{lllll}
\hline $\begin{array}{l}\text { Neighborhood of } \\
\text { residence }\end{array}$ & \multicolumn{2}{l}{ Tendency to integrate: } & & N \\
\hline Lttawa & Low (\%) & Medium (\%) & High (\%) & \\
Hull & 39 & 38 & 24 & 72 \\
\hline
\end{tabular}


community also has an effect, since over half the Hull speakers are high 'integrators', while the same is true of less than a quarter of their Ottawa counterparts. Other factors, like socioeconomic class membership, have no effect. These results appear to support the claims of Haugen (1950) and Mougeon et al. (1985a) regarding the inhibiting role of bilingual ability on loanword integration. They do not, however, invalidate our finding of increasing phonological integration with age of attestation and with frequency of use, effects which cross-cut that of bilingual ability. (An analysis of variance shows both proficiency and neighborhood to have significant effects on integration.) Thus, proficient English speakers use less French phonology than monolinguals, but all speakers integrate old and widespread loanwords more than they do nonce borrowings.

We have shown in sections 4.2-4.4 that English-origin words are integrated into French linguistic patterns immediately upon, or shortly after, their introduction into the language. It is only at the phonological level that integration is a gradually increasing function of age of attestation and frequency of usage. Thus the basic stock of loanwords in Canadian French (that is, the oldest, most pervasive types) consists of words that for all intents and purposes are indistinguishable from their French counterparts.

We noted earlier that many tokens of English origin used in the region do not form part of the basic loanword stock. These include idiosyncratic and nonce borrowings, but also recurrent loanwords of lesser frequencies. We investigate next the patterns of usage of these (as well as the widespread) loanwords, as we examine the characteristics of the loanword users.

\subsection{Social influences on rates and patterns of loanword usage}

Various characteristics of an individual may be expected to affect her behavior with regard to use of borrowings. These include such standard sociolinguistic factors as sex, age, and educational attainment, as well as personal bilingual ability and the prevailing norms of the speech community in which she resides. In this section we investigate each of these factors to determine which, if any, are predictive of borrowing rates (in terms of types and tokens) and/or patterns (preference for nonce vs. widespread loanwords).

To do this, we first calculate a borrowing profile for each speaker in the sample: the proportion of borrowed tokens and types in her interview, and the proportions of these which were nonce or widespread. ${ }^{27}$ 


\subsection{Analysis of variance}

Two series of analyses of variance (ANOVA) were carried out measuring the effects, on each of the four proportions in the loanword profile, of neighborhood, age, sex, proficiency in English, and occupational class. ${ }^{28}$ (Preliminary statistical manipulations indicated that educational attainment had little or no independent effect, on any of the borrowing proportions).

The main results, to be described in more detail below, are as follows:

1. Social class membership is the major determinant of overall borrowing RATES, in terms of both tokens and types, with the workingclass groups leading middle-class speakers. Neighborhood also has an important effect, largely due to the contrast between Hull women and Ottawa residents.

2. Class, however, has no systematic influence on borrowing PATTERNS. Here neighborhood of residence is the major determinant; Ottawans use a higher proportion of nonce, and a lower proportion of widespread, loans than Hull speakers.

3: There are clear sex-based distinctions in both rates and patterns in Hull, women using loanwords less overall, fewer different loan types, fewer nonce loans, and a higher proportion of widespread loans than men. There is no such distinction for Ottawa.

4. Both a speaker's age and English proficiency (the latter correlated with neighborhood $[\mathrm{r}=.37]$, age $[\mathrm{r}=.19]$, and, in Hull, sex $[\mathrm{r}=.27]$ ) have systematic but generally only marginally significant effects, particularly on borrowing patterns. Younger speakers proficient in English have higher borrowing rates and use significantly more nonce and fewer widespread loans than the others.

These results do not emerge clearly at first when ANOVA is applied directly to the entire data set. Table 5 summarizes the significance levels of factor effects on proportions of tokens, types, nonce borrowings, and widespread loans, in each case based on the three factors which minimize the error sum of squares for the dependent variable (except for proportion of loan types, where an analysis including the nonsignificant factor of English proficiency instead of sex has a slightly lower error sum of squares).

Here both class and neighborhood have highly significant effects on borrowing rates (tokens and types), while each of sex and neighborhood have a strong effect on patterns (nonce and widespread loans). These results must be viewed, however, in the light of the interaction effects also evident in Table 5.

In three of the four analyses the interaction between neighborhood and 
Table 5. Best three-way ANOVA significance levels for borrowing proportions (full data set)

\begin{tabular}{|c|c|c|c|c|}
\hline \multirow[t]{2}{*}{ Factor } & \multicolumn{3}{|c|}{ Significance level (P-value) } & \multirow[b]{2}{*}{ widespread } \\
\hline & $\begin{array}{l}\text { Rate: } \\
\text { tokens }\end{array}$ & types & $\begin{array}{l}\text { Pattern: } \\
\text { nonce }\end{array}$ & \\
\hline Class & 0.00 & 0.00 & - & - \\
\hline Neighborhood & 0.00 & 0.00 & 0.00 & 0.00 \\
\hline Sex & 0.18 & 0.34 & 0.01 & 0.01 \\
\hline Age & - & - & 0.18 & 0.03 \\
\hline Neighborhood $\times \operatorname{sex}$ & 0.04 & 0.07 & 0.31 & 0.01 \\
\hline Neighborhood $\times$ class & 0.63 & 0.36 & - & - \\
\hline Sex $\times$ class & 0.21 & 0.21 & - & - \\
\hline Age $\times$ sex & - & - & 0.34 & 0.35 \\
\hline Age $\times$ neighborhood & - & - & 0.27 & 0.62 \\
\hline $\begin{array}{l}\text { Class } \times \text { neighborhood } x \\
\text { sex }\end{array}$ & .0 .71 & 0.91 & - & - \\
\hline $\begin{array}{l}\text { Age } \times \text { neighborhood } \times \\
\text { sex }\end{array}$ & - & - & 0.88 & 0.92 \\
\hline
\end{tabular}

sex is clear, and in the case of nonce borrowings, examination of the data suggests that it is the inappropriateness of the additive model in ANOVA which is responsible for the significance of the simple sex effect rather than the interaction term.

In all four cases, it is clear that the interaction is due to the strong difference between women's and men's use of borrowings in Hull, a distinction which is completely absent in Ottawa. In fact, the Hull men's behavior can be seen to lie halfway between their female counterparts on the one hand and the Ottawa speakers, male and female, on the other. It is not difficult to explain this result. Fourteen of the 24 Hull men have worked in Ottawa; this is true of only seven of the Hull women. Three of the men had some schooling in Ottawa and one had actually lived there, while none of the women had. Thus it is safe to consider that the women manifest a 'purer' version of Hull linguistic performance, while many of the men, who have worked, studied, and/or lived in Ottawa, have been influenced by Ottawa patterns. Thus the sex effects and their interaction with neighborhood in Table 5 are really reflections of neighborhood differences, where some of the men coded as Hullois should be considered to manifest speech patterns partly representative of Ottawa, and partly of Hull.

These considerations motivated a reanalysis of the data, with one of the 
groups responsible for the interactions, the female speakers from Hull, analyzed separately from the rest of the speakers (Table 6). This effectively removed all sex differences from the data, as well as most of the neighborhood effect on overall borrowing rates. For the main group of speakers, occupational class exercised the only significant effect on borrowing rate for both tokens and types. Hull speakers of all classes still borrow less, but the difference is only marginally significant, and only with respect to types.

As far as borrowing pattern is concerned for the speakers in Table 6, only neighborhood has a significant effect on nonce proportions. English proficiency shows a systematic but nonsignificant effect. As for widespread loans, proficiency is clearly significant with the more proficient speakers using proportionately fewer widespread loans, while neighborhood shows up in an interaction effect with class: in Hull, middle-class speakers tend to avoid widespread borrowings, while in Ottawa, they tend to favor them.

The separate analysis of the female speakers from Hull summarized in Table 7 shows occupational class to be explanatory of overall rates, as is the case for the main group of speakers. Neighborhood differences no longer being pertinent within the group, there were no significant factor

Table 6. Best three-way ANOVA significance levels for borrowing proportions (Hull women excluded)

\begin{tabular}{|c|c|c|c|c|c|}
\hline Factor & $\begin{array}{l}\text { Signifi } \\
\text { Rate: } \\
\text { tokens }\end{array}$ & $\begin{array}{l}\text { vel (P- } \\
\text { types }\end{array}$ & & $\begin{array}{l}\text { Pattern: } \\
\text { nonce }\end{array}$ & widespread \\
\hline Class & 0.04 & 0.02 & & - & 0.50 \\
\hline Neighborhood & 0.32 & 0.10 & & 0.05 & 0.99 \\
\hline Proficiency & 0.45 & 0.39 & & 0.17 & 0.01 \\
\hline Age & - & - & & 0.59 & - \\
\hline Neighborhood $\times$ class & 0.72 & 0.53 & & - & 0.07 \\
\hline Proficiency $\times$ class & 0.85 & 0.82 & & - & 0.57 \\
\hline $\begin{array}{l}\text { Neighborhood } \times \\
\text { proficiency }\end{array}$ & 0.46 & 0.45 & & 0.99 & 0.65 \\
\hline Neighborhood $\times$ age & - & - & & 0.60 & - \\
\hline Age $\times$ proficiency & - & - & & 0.36 & - \\
\hline $\begin{array}{l}\text { Class } \times \text { neighborhood } \\
\times \text { proficiency }\end{array}$ & 0.73 & 0.55 & & - & 0.21 \\
\hline $\begin{array}{l}\text { Age } \times \text { neighborhood } \times \\
\text { proficiency }\end{array}$ & - & - & & 0.53 & - \\
\hline
\end{tabular}


Table 7. Best two-way ANOVA significance levels for borrowing proportions (Hull women only)

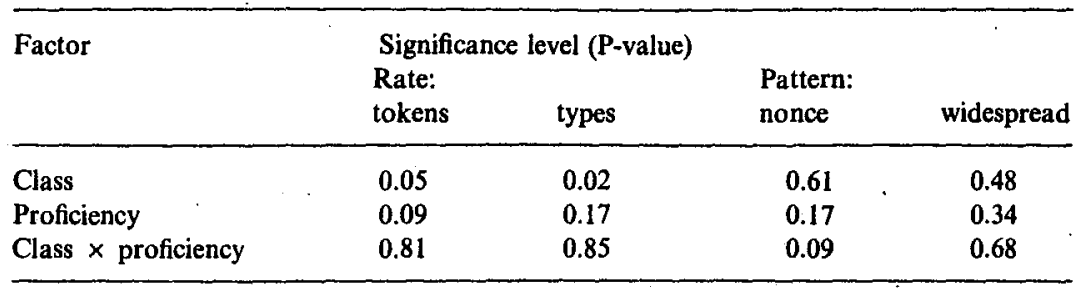

effects on borrowing patterns. Proficiency had a systematic effect on increasing tokens, types, and nonce borrowings, but with only 24 speakers, the differences were not large enough to be significant.

\subsection{Neighborhood}

The binary distinctions for the independent variables used in the previous section help establish statistical significance but, in the case of neighborhood, mask some of the detailed differences among the various areas of Ottawa and Hull. Table 8 shows the borrowing profile for the individual neighborhoods.

As we have seen, in both overall borrowing rate and borrowing pattern, there are consistent differences between the Ontario and Quebec neighborhoods. The direction of these differences suggests that borrowing is a function of the amount of exposure to English in the environment: the highest rates (of both tokens and types) are found in the Ottawa communities, consistent with their location in anglophone Ontario and the number of English mother-tongue claimants within them (Figure 1),

Table 8. Distribution of borrowings across neighborhoods

\begin{tabular}{|c|c|c|c|c|c|}
\hline Average $\%$ & $\begin{array}{l}\text { Ottawa: } \\
\text { West } \\
\text { End }(\%)\end{array}$ & $\begin{array}{l}\text { Basse- } \\
\text { Ville (\%) }\end{array}$ & $\begin{array}{l}\text { Vanier } \\
(\%)\end{array}$ & $\begin{array}{l}\text { Hull: } \\
\text { Vieux } \\
\text { Hull (\%) }\end{array}$ & $\begin{array}{l}\text { Mont } \\
\text { Bleu }(\%)\end{array}$ \\
\hline Borrowed tokens/all tokens & 1.20 & 0.90 & 0.85 & 0.72 & 0.51 \\
\hline Borrowed types/all types & 4.7 & 3.8 & 3.4 & 2.8 & 1.9 \\
\hline $\begin{array}{l}\text { Nonce borrowings/ } \\
\text { borrowed types }\end{array}$ & 14.5 & 12.1 & 12.1 & 6.9 & 5.6 \\
\hline $\begin{array}{l}\text { Widespread } \\
\text { loans/borrowed types }\end{array}$ & 51 & 53 & 57 & 62 & 65 \\
\hline
\end{tabular}


while the lowest are associated with the two virtually monolingual French communities in Quebec. (We know from the ANOVA that these low rates are especially true of Hull women.) Indeed, borrowing rates decline steadily as the ratio of anglophones to francophones decreases, with the middle-class Mont Bleu neighborhood in Hull showing the lowest of all. Figure 8 depicts graphically the complex relationship between speakers' borrowing patterns and environmental exposure to English as determined by neighborhood of residence.

Nonce borrowings can be seen to be concentrated in the Ontario neighborhoods where English input is readily available, with the proportion they represent of the total lexicon again decreasing steadily as we move from the highly bilingual West End to Mont Bleu. The reverse is true of widespread loans which, proportionally speaking, are preferred in Hull. Recall that their use, in contrast to that of nonce borrowings, does not necessarily imply knowledge of English. The striking regularity of this pattern, ${ }^{29}$ however, obscures another cross-cutting effect, which we attribute to social-class pressures on loanword usage, related to the socialclass effects found in the ANOVA in the previous section. This emerges from comparing the absolute numbers of borrowed types and widespread loans used in the different neighborhoods (the top two broken lines in Figure 8): the tendency for both types and widespread loanwords to

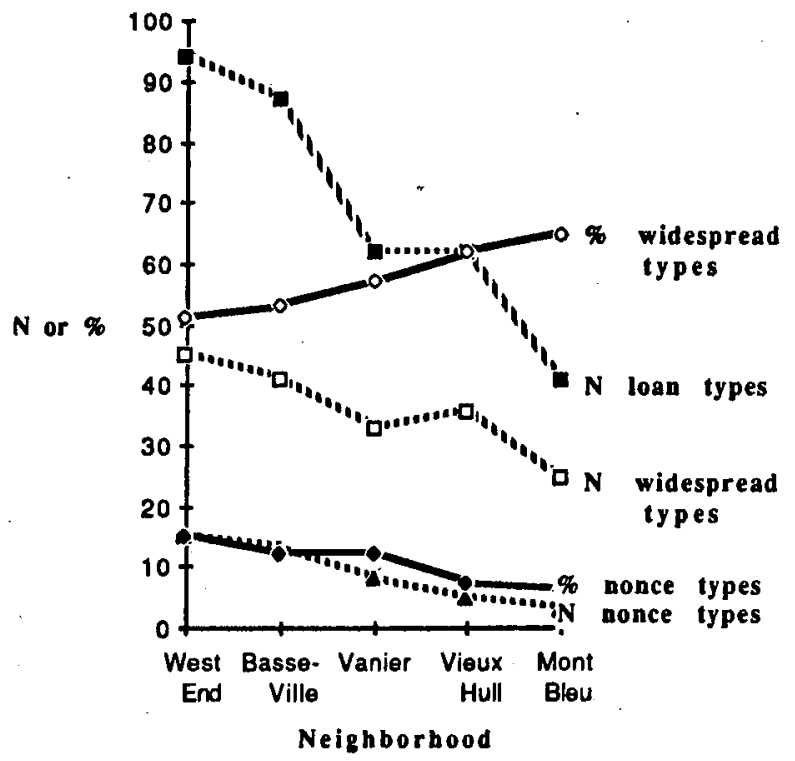

Figure 8. Borrowing patterns in Ottawa-Hull neighborhoods 
decrease in frequency as we move from Ontario to Quebec is interrupted between Vanier and Vieux Hull, the first of which uses fewer, and the second more, different types and widespread loanwords than expected.

Figure 9 plots the relative position of the neighborhoods to each other with regard to nonce and widespread borrowings. The West End and Basse-Ville of Ottawa have the highest number of nonce borrowings (that they also have the highest numbers of widespread words is due to their generally inflated borrowing rates, seen in Table 8), while.Vieux Hull and Mont Bleu show the lowest. Note, however, that speakers from Vieux Hull use more widespread borrowings (and more different types) than those from Mont Bleu, a finding that has no ready explanation based on the bilingual makeup of the two neighborhoods, which is quite similar. ${ }^{30}$ Instead, as indicated by the interaction in Table 6, it is due to prevailing social pressures in Mont Bleu, which contains the largest proportion of informants ranking high on the socioeconomic scale of any of the neighborhoods studied. Such normative pressures presumably militate against the use of recognized loanwords and would explain the reduced rate of borrowing in this community. Note that this avoidance extends even to established loanwords, which might have been expected to escape such monitoring strategies, considering they are transmitted along with the native French lexicon. Rather, they are apparently subject to the same kind of conscious control as the remainder of the vocabulary. This suggestion is corroborated by the very conservative attitudes toward (and self-reports of) bilingual behavior in general of Mont Bleu speakers (Poplack and Miller 1985). The position of Vanier is intermediate to that of the other neighborhoods: it uses fewer borrowed types and nonce

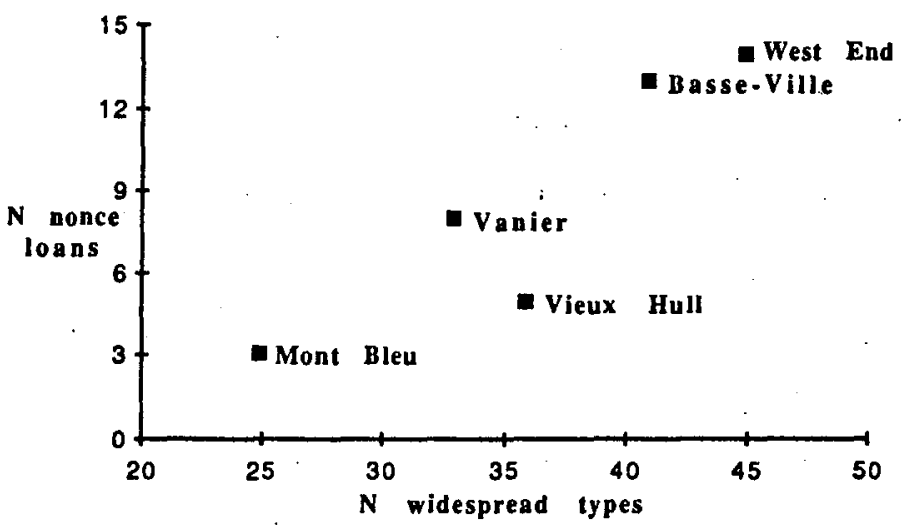

Figure 9. Nonce and widespread borrowings in five neighborhoods 
borrowings than its Ottawa counterparts, and fewer widespread borrowings than even Vieux Hull. We showed in the last section that nonce borrowing was at least weakly associated with superior bilingual ability. Thus it is striking that while Vanier actually contains the greatest proportion of individuals ranked high in English proficiency of any neighborhood studied (Table 9), it still lags behind both Basse-Ville and the West End in the use of nonce borrowings.

We suggest that the behavior of Vanier vis-à-vis the other Ottawa communities parallels that of Mont Bleu with regard to Vieux Hull, whereby social pressures against using loanwords inhibit any favorable effect of English proficiency on borrowing. Note, however, that while the absolute number of widespread loans is reduced in Vanier along with the number of types, these widespread loans actually form a higher proportion of the different borrowed types than in the other Ottawa communities. This accounts for the opposing tendencies found in the ANOVA for middle-class speakers in Hull and Ottawa to disfavor and to favor widespread loans, respectively. Ottawa speakers are presumably less conditioned to be sensitive to these established importations from English, treating them as part of the received French lexicon, while the Quebecois speakers of Hull would have been alerted to their status as common anglicisms.

Table 9. Speakers' English proficiency by neighborhood

\begin{tabular}{llllllr}
\hline Proficiency in English & $\begin{array}{l}\text { West } \\
\text { End (\%) }\end{array}$ & $\begin{array}{l}\text { Basse- } \\
\text { Ville (\%) }\end{array}$ & $\begin{array}{l}\text { Vanier } \\
(\%)\end{array}$ & $\begin{array}{l}\text { Vieux } \\
\text { Hull (\%) }\end{array}$ & $\begin{array}{l}\text { Mont } \\
\text { Bleu (\%) }\end{array}$ & N \\
\hline Low & 17 & 21 & 17 & 42 & 42 & 33 \\
Mid-low & 25 & 33 & 21 & 29 & 50 & 38 \\
Mid-high + high & 58 & 46 & 62 & 30 & 8 & 49 \\
\hline
\end{tabular}

\subsection{Age}

The ANOVA results do not argue strongly that an individual's age also affects his use of borrowed vocabulary. Comparison of borrowing rates among the six age groups (Table 10), however, shows that the proportion borrowings represent of the total vocabulary tends to decrease slightly though consistently with age, such that the youngest groups (aged 15-34) use significantly ( $\mathrm{p}<.01$, in a likelihood ratio test) more borrowings than their elders (aged 65 and over), and these in turn represent a significantly $(p<0.01)$ greater proportion of their total lexical types. That this did not 
Table 10. Distribution of borrowings across age groups

\begin{tabular}{|c|c|c|c|c|c|c|}
\hline \multirow[t]{2}{*}{ Average $\%$} & \multicolumn{3}{|c|}{ Speaker age: } & \multirow[b]{2}{*}{$45-54$} & & \multirow[b]{2}{*}{$65+$} \\
\hline & $15-24$ & $25-34$ & $35-44$ & & $55-64$ & \\
\hline $\begin{array}{l}\text { Borrowed tokens/all } \\
\text { tokens }\end{array}$ & 1.1 & 0.96 & 0.88 & 0.67 & 0.81 & 0.63 \\
\hline $\begin{array}{l}\text { Borrowed types/all } \\
\text { types }\end{array}$ & 4.1 & 3.6 & 3.6 & 2.9 & 3.3 & 2.5 \\
\hline $\begin{array}{l}\text { Nonce borrowings/ } \\
\text { borrowed types }\end{array}$ & 12.8 & 9.8 & 11.3 & 8.9 & 8.0 & 10.7 \\
\hline $\begin{array}{c}\text { Widespread loans/ } \\
\text { borrowed types }\end{array}$ & 52 & 56 & 56 & 63 & 61 & 57 \\
\hline
\end{tabular}

appear in the ANOVA is partly a function of collapsing age groups, and partly due to the negative correlation of age and English proficiency.

The polar age groups favor idiosyncratic and/or nonce borrowings, while the middle groups (ages 45-64) use somewhat more widespread and recurrent loans. The clear generational differences imply the existence of at least one type of process of change affecting the borrowed lexical stock, that is, that new words are being added to this vocabulary in the form of idiosyncratic (and possibly nonce) borrowings. From the distribution of nonce borrowings in Table 10 it appears that the groups responsible for these innovations are the oldest and youngest sectors of the society. However, closer examination of the data suggests that it is in fact only the youngest speakers who are innovating, while those over 65 use obsolete or archaizing terms. This is to some extent a function of the individual's bilingual ability. Indeed, there are more highly bilingual speakers $(45 \%)$ who would be capable of nonce borrowing in the youngest group than among the older speakers (25\%).

\subsection{Concentration and distribution of loanwords}

The fact that widespread loanwords constitute a large proportion of the average speakers' borrowed vocabulary means that the stocks of Englishorigin words of any two speakers will tend to contain at least a few words in common. The statistical results in the preceding sections, however, could have been obtained equally well in the context of relatively little average sharedness among speakers as in a situation of high sharedness. In particular, it is quite possible that widespread words achieve that status only within single neighborhoods and are not used by the rest of the community. This leads to the question of whether Ottawa-Hull franco- 
phones can be considered to have a single, shared pool of loanwords (especially the frequently used ones) or whether each neighborhood, age group, sex, or occupational class has its own characteristic stock of borrowed vocabulary. The answer to this question may also enable us to discover the direction of diffusion of loanwords, and of new vocabulary in general, within the community.

We thus ascertained whether some borrowed types are restricted in scope, that is, concentrated in a particular subgroup of the population. We then compared the average age of attestation of the loans associated with the different subgroups. Since, however, most borrowed types occur only once, we limited this part of the study to a subsample of words which recur relatively frequently. For each of the sociodemographic groupings, we extracted all those loanwords used a minimum of five times in the corpus and which could be said to be associated to a given extent with the group (for example, those which were used more than $40 \%$ of the time in a single neighborhood). ${ }^{31} \mathrm{~A}$ good proportion of these were attested in our historical sources and we could thus meaningfully compare our groupings with respect to the attestation history of the loans associated with each.

\subsection{English proficiency}

It has often been claimed that the most highly bilingual speakers play a different role from the rest of the community in the borrowing process, as importers of phonological innovations from the source language (Haugen 1950, 1956; Mougeon et al. 1985a), and as agents of loanword diffusion (Mougeon et al. 1985c). We have seen some evidence in favor of the first claim (Table 3), but Table 6 suggests that their major role is one of lexical innovation: their inflated borrowing rates are in fact due to a predilection for nonce borrowing rather than the use of widespread loans. Their greater knowledge and use of English explain why they can resort to nonce loans (to fill whatever discourse function) much more frequently than those less familiar with the language, who prefer widespread and recurrent loanwords. These results run counter to the one reported in Mougeon et al. (1985c: 18) where the (widespread) loanword so was preferred by mid-level French users (the more English-proficient speakers purportedly shunning it so as not to call attention to their imperfect mastery of French, while the high French users reject the symbolic value associated with use of English). In Ottawa-Hull it is precisely the lessbilingual speakers who favor widespread loanwords; that is, those that are transmitted along with the French lexicon and require no prior knowledge of English to use. This suggestion is supported by an examination of some of the loanwords associated with these speakers (14). Though these, 
Table 11. Attestations of loanwords associated with each language proficiency group

\begin{tabular}{|c|c|c|c|c|}
\hline English proficiency & $\begin{array}{l}\text { Date of attest } \\
\text { Before } 1930 \\
(\%)\end{array}$ & After $1970(\%)$ & Unattested (\%) & $\mathbf{N}$ \\
\hline Low & 49 & 29 & 9 & $44^{32}$ \\
\hline Mid-low & 48 & 16 & 22 & 96 \\
\hline Mid-high & 30 & 18 & 41 & 74 \\
\hline High & 27 & 4 & 58 & 26 \\
\hline
\end{tabular}

by definition, exclude both nonce and idiosyncratic borrowings, they nonetheless allow us to characterize the remainder of the lexicon associated with each subgroup. For example, most Canadian francophones would recognize the use of bad luck, mop, shop, and tramway, but perhaps not low-rental, cashier, and pull.

(14) Selected lexical entries associated (at 40\%) with English proficiency groups:

\begin{tabular}{|c|c|c|c|}
\hline $\begin{array}{l}\text { Low } \\
\text { alley 'marble' } \\
\text { bad luck } \\
\text { boiler (n) } \\
\text { mop } \\
\text { shop 'factory' } \\
\text { swamp } \\
\text { traite 'treat' } \\
\text { tramway }\end{array}$ & $\begin{array}{l}\text { Mid-low } \\
\text { appointement } \\
\text { bar } \\
\text { bargain } \\
\text { boys 'the guys' } \\
\text { canceller 'cancel' } \\
\text { fancy } \\
\text { jumper (v) } \\
\text { mail } \\
\text { shaver (v) } \\
\text { spot 'place' } \\
\text { waiter }\end{array}$ & $\begin{array}{l}\text { Mid-high } \\
\text { beach } \\
\text { bright 'intelligent' } \\
\text { customer } \\
\text { dad } \\
\text { good! } \\
\text { motorcycle } \\
\text { phoner (v) } \\
\text { senior-citizen } \\
\text { too much! }\end{array}$ & $\begin{array}{l}\text { High } \\
\text { ball } \\
\text { cashier } \\
\text { good-bye } \\
\text { low-rental } \\
\text { my gosh! } \\
\text { pull 'influence' } \\
\text { right }\end{array}$ \\
\hline
\end{tabular}

The selection of lexical entries in (14), taken together with the figures in Table 11 (based on the full sample of loanwords associated with each proficiency group) shows that speakers with lesser proficiency in English favor loanwords of long standing (attested before 1930), while their more bilingual counterparts show a strong preference for unattested words.

Differences between proficiency groups may also be seen in the grammatical categories of loanwords they favor. The least-bilingual speakers use somewhat more nouns $(67 \%$ of all loanwords associated with them) than their more proficient counterparts $(61 \%) .{ }^{33}$ Thus we can confirm that highly bilingual speakers are importers of lexical innovations, as evidenced by their preference for nonce and unattested borrowings. 


\subsection{Neighborhood of residence}

The figures in Table 12 show the Hull communities to clearly favor established loanwords over recent ones, while the opposite is true of the Basse-Ville and the West End of Ottawa. The latter nonetheless shows significantly more established borrowings. Vanier, as in section 5.2 , is intermediate. Its loanwords are almost evenly divided between established and recent or unattested. The examples in (15) illustrate these trends.

(15) Selected lexical entries associated (at $40 \%$ ) with each neighborhood:

\begin{tabular}{|c|c|c|c|c|}
\hline $\begin{array}{l}\text { West End } \\
\text { abortion } \\
\text { bunch } \\
\text { capital . } \\
\text { punishment } \\
\text { customer } \\
\text { first } \\
\text { garbage } \\
\text { layoffer (v) } \\
\text { mistake } \\
\text { order (v) } \\
\text { short '-of' } \\
\text { végétable } \\
\text { 'unconscious } \\
\text { person' }\end{array}$ & $\begin{array}{l}\text { Basse-Ville } \\
\text { bat (baseball) } \\
\text { cartoon } \\
\text { computerized } \\
\text { dishwasher } \\
\text { free } \\
\text { high-class } \\
\text { jumper (v) } \\
\text { low rental } \\
\text { no wonder } \\
\text { senior citizen }\end{array}$ & $\begin{array}{l}\text { Vanier } \\
\text { canner (v) } \\
\text { drink } \\
\text { easy } \\
\text { luck, -y } \\
\text { mop } \\
\text { teenager } \\
\text { high-rise } \\
\text { weird }\end{array}$ & $\begin{array}{l}\text { Vieux Hull } \\
\text { baloney } \\
\text { bar } \\
\text { bill } \\
\text { dump (n) } \\
\text { foreman } \\
\text { mop } \\
\text { warehouse } \\
\text { runneur } \\
\text { superviser } \\
\text { thrill }\end{array}$ & $\begin{array}{l}\text { Mont Bleu } \\
\text { barbecue } \\
\text { pamphlets } \\
\text { scout } \\
\text { set } \\
\text { stop [sign] } \\
\text { punk }\end{array}$ \\
\hline
\end{tabular}

The differences between the neighborhoods are also evidenced by the grammatical categories of loanwords associated with them. In each of the three Ottawa neighborhoods, nouns, the most frequently borrowed category, do not exceed $56 \%$ to $63 \%$ of the borrowed forms, with the remaining data divided among adjectives, verbs, expressions, and, in a few

Table 12. Recency of loanword stock associated with each neighborhood

\begin{tabular}{llrrr}
\hline Neighborhood & \multicolumn{2}{c}{$\begin{array}{l}\text { Date of attestation: } \\
\text { Prior to 1930 (\%) }\end{array}$} & After $1970(\%)$ & Unattested (\%) \\
\hline West End & 31 & 9 & 51 & 77 \\
Basse-Ville & 22 & 22 & 47 & 68 \\
Vanier & 40 & 8 & 40 & 25 \\
West End & 52 & 14 & 20 & 44 \\
Mont Bleu & 57 & 14 & 14 & 14 \\
\hline
\end{tabular}


cases, adverbs. In Hull, on the other hand, the proportion nouns represented of the total is inflated to $80 \%$, with the other, more 'innovative' categories underrepresented.

\subsection{Occupational class and educational level}

When we examine the loanword stock associated with each occupational group, we find no consistent differentiation between the groups based on use of established versus recently or not yet attested borrowings. However, a class distinction does appear in the grammatical categories favored by each subgroup. Unskilled workers and the chronically unemployed use far fewer nouns (55\%), with concomitantly more loanwords distributed across the more 'innovative' parts of speech, than do members of the other occupational classes ( $66 \%$ to $77 \%$ nouns), suggesting that not only borrowing, but particularly borrowing into any other than the most common category, is stigmatized by the latter groups.

Similarly with educational attainment; we noted only a slight tendency for old established loanwords to be concentrated among speakers with primary schooling or less, while recent or unattested forms are preferred by those with secondary education. This finding cannot of course be interpreted as evidence that schooling plays a direct role in borrowing patterns, except perhaps insofar as it provides instruction in English, particularly at the secondary-school level. In effect, half of the speakers with some secondary schooling rate mid-high or better in English proficiency, while this is true of only a third of those with primary education. Speakers with least proficiency in English are of course precisely those who favor the older borrowings.

\subsection{Age}

The characteristics of borrowed vocabulary are very different among the different age groups. The results in Table 13 indicate that many of the items associated with the youngest age group refer to cultural phenomena of the past few decades, a full $65 \%$ of which have either not yet or only recently penetrated the general French lexicon. Speakers over 65 show a reversal: here the majority $(59 \%)$ are very old and well-established loanwords (most having been attested before 1900), many of which are no longer or only infrequently used by speakers under 55 , such as beans, chesterfield, dumper (v), mop, ginger ale, ice-cream. On the other hand, the lexical stock associated with the two middle groups (ages 45-64) is more evenly distributed among old, established forms attested before 1930 and 
Table 13. Attestations of loanword stock associated (at 40\%) with age groups

\begin{tabular}{llccc}
\hline Speaker age & $\begin{array}{l}\text { Date of attestation: } \\
\text { Prior to 1930 (\%) After } 1970(\%)\end{array}$ & Unattested (\%) & \\
\hline $15-34$ & 14 & 22 & 43 & 69 \\
$45-64$ & 48 & 15 & 27 & 34 \\
$65+$ & 59 & 0 & 24 & 29 \\
\hline
\end{tabular}

recently attested or still unattested ones. These constitute a better reflection of the loanword stock in current use, and indeed, many are familiar from the wider Canadian French lexicon. These trends are illustrated by the examples in (16):

(16) Selected lexical entries associated (at 40\%) with age groups:

\begin{tabular}{|c|c|c|}
\hline $\begin{array}{l}15-34 \\
\text { arcade } \\
\text { bande 'musical __' } \\
\text { comics } \\
\text { drink } \\
\text { drive-in } \\
\text { joint 'marijuana' } \\
\text { motorcycle } \\
\text { pitcher (v) } \\
\text { punk } \\
\text { rock } \\
\text { sharp } \\
\text { sleigh } \\
\text { shaver }\end{array}$ & $\begin{array}{l}45-64 \\
\text { bachelor '_ apartment' } \\
\text { ball } \\
\text { catch } \\
\text { hamburger } \\
\text { hobby } \\
\text { jumper (v) } \\
\text { one way . } \\
\text { runneur 'delivery man' } \\
\text { sport } \\
\text { tank } \\
\text { végétable }\end{array}$ & $\begin{array}{l}65+ \\
\text { beans } \\
\text { chesterfield } \\
\text { clairer 'to fire' } \\
\text { coppe 'copper' } \\
\text { crique 'creek' } \\
\text { foreman } \\
\text { luck } \\
\text { mop } \\
\text { notice 'give -' } \\
\text { set 'dance' }\end{array}$ \\
\hline
\end{tabular}

The innovative behavior of the youngest speakers with regard to loanword usage is corroborated by an examination of the grammatical categories in which their borrowings are concentrated. Their loanwords fall into the category of nouns no more than $50 \%$ of the time, with the remainder distributed across five other parts of speech. Loanwords associated with the oldest speakers, on the other hand, consist of many more $(74 \%)$ nouns, with the resulting lesser representation of other parts of speech. 


\subsection{Sex}

When we look for words that are confined to one or the other sex, for women we find words related to furniture, food, etc., while the words favored by men tend to relate to sports and the workplace, as with the examples in (17). It should be obvious that these results do not tell us anything specifically about borrowing, but rather mirror sex-specific differences in topic of conversation and/or vocabulary as a whole.

(17) Selected lexical entries associated (at $85 \%$ or better) with men and women:

$\begin{array}{ll}\begin{array}{l}\text { Men } \\ \text { bat } \\ \text { dumper (v) }\end{array} & \begin{array}{l}\text { Women } \\ \text { alley 'marble' } \\ \text { bathing suit } \\ \text { golf } \\ \text { hobby }\end{array} \\ \begin{array}{l}\text { dryer } \\ \text { girl friend }\end{array} \\ \text { right } & \begin{array}{l}\text { half and half } \\ \text { hopscotch }\end{array} \\ \text { runneur } & \text { marbles } \\ \text { shape 'to be in _, } & \text { mean(y) } \\ \text { softball } & \text { part-time } \\ \text { supervisor } & \text { shower 'baby _- } \\ \text { switcher (v) } & \\ \text { wagon } & \end{array}$

Examination of the loanword stock actually associated with each sex (Table 14) shows that men, and not women, favor established loanwords. Similarly, men borrow more (71\%) nouns than women $(61 \%)$. Given the sparse data, these differences are not significant, and we must rely on the

Table 14. Attestations of loanwords associated (at $85 \%$ ) with each sex

\begin{tabular}{|c|c|c|c|c|}
\hline \multirow[t]{2}{*}{ Sex } & \multicolumn{3}{|c|}{ Date of attestation:- } & \multirow[t]{2}{*}{$\mathbf{N}$} \\
\hline & Before $1930(\%)$ & After $1970(\%)$ & Unattested (\%) & \\
\hline Men & 40 & 13 & 37 & 30 \\
\hline Women & 22 & 4 & 58 & 26 \\
\hline
\end{tabular}

ANOVA results, which indicate more innovative use of borrowings on the part of male than female speakers in Hull only. 


\subsection{Sharedness of loanwords}

Though we have established a certain specificity of loanword stock within various subgroups of the population, it remains to evaluate the universality versus specificity of the vocabulary in a quantitative manner.

In trying to infer the channels of diffusion of loanwords within the community, the key data on any pair of individuals in the community are how many borrowed types they use in common and how many each uses that the other does not. Two individuals from segments of the community in close-enough linguistic contact that diffusion occurs readily should share many borrowed words, whereas those who represent segments relatively isolated from each other might be expected to have rather different stocks of borrowings.

From the figures for all pairs of individuals, we could estimate for any two groups, A and B, the average number of shared borrowings, namely the sum of the pairwise scores of each individual in A with each individual in B, divided by the number of such speaker pairs. Similarly, we could calculate the average number of borrowings shared by two speakers within a single group, the groups being the six age groups, the five communities, the two sexes, the four language-proficiency groups, and the four occupational classes.

One methodological problem is posed by the fact that two speakers who each use many borrowed words are more likely to use some in common, if only by coincidence, whether or not they truly share a disproportionate part of their vocabularies. To control for this, we also calculated for each pair of speakers the number of borrowings they could be expected to share, given the total of types used by each, according to a random model of homogeneous use of borrowed vocabulary where all speakers have the same probabilities of choosing the various words, though some choose more than others. ${ }^{34}$ We could thus predict the number of words in common and subtract the average predicted value from the average observed shared borrowing scores for each pair of groups, to arrive at a true indication of whether the two groups have higher or lower sharedness of borrowed words than the overall community average. The figures in the tables below can be interpreted as the average number of borrowings shared by pairs of individuals in the pertinent groups, in excess of (positive numbers) or less than (negative figures) the value predicted by the random model.

The most important outcome of the calculations is that the results vary from about -2 to +2 . Since the predicted number of shared borrowings for a given pair of speakers is usually in the range from 10 to 20, the 
variation in number of borrowings shared seldom exceeds $\pm 20 \%$ of what is predicted and in most cases is within $\pm 5 \%$.

In other words, the amount of borrowed vocabulary shared by OttawaHull speakers in different neighborhoods, classes, age groups, sexes, and English-proficiency categories is not very different from what would be predicted were there just one uniform pool of borrowed words for the community and each speaker chose from this pool independent of his or her membership in a particular subgroup. In the terms of LePage and Tabouret-Keller (1980), the francophones of the Ottawa-Hull region are 'focussed' on a shared strategy for incorporating English lexical items into French discourse.

There are, however, some systematic, if small, deviations from this overall tendency. One of these is the pattern of sharedness among the age groups. In sections 5.3 and 6.4 we found, in the usage rates of various categories of borrowings, that the youngest speakers borrow in an innovative manner, using large numbers of borrowed words, with a high proportion of nonce borrowings. Many of the borrowings used by older speakers were also rare, but this could be attributed to the obsolescence of these items. Those aged between 45 and 64 used the lowest proportion of nonce borrowings and the highest of widespread loans. Calculation of sharedness values clarifies this distribution.

Table 15 confirms the generational discontinuities in the sample. The youngest age group, which we saw from Table 10 to have the highest average number of borrowings, has low sharedness with all the other age groups, including itself $(-1.6)$, which reflects the diversity of usage of borrowed vocabulary among its members (expressed in Table 10 by their propensity to use more nonce and idiosyncratic borrowings than other speakers). They have the lowest rate with the oldest group $(-2.0)$, indicating that the two groups have the most differences in their stocks of borrowed words. The same pattern holds for the 25-34-year-olds, but this

Table 15. Sharedness among age groups

\begin{tabular}{lrrrrrr}
\hline Age & $15-24$ & $25-34$ & $35-44$ & $45-54$ & $55-64$ & $65+$ \\
\hline $15-24$ & -1.6 & -1.2 & -0.7 & -0.5 & -1.4 & -2.0 \\
$25-34$ & & 0.0 & 0.2 & 0.6 & -0.2 & -1.0 \\
$34-44$ & & & 0.7 & 1.3 & 0.8 & -0.3 \\
$45-54$ & & & & 2.1 & 2.3 & 0.6 \\
$55-64$ & & & & & 2.0 & 0.7 \\
$65+$ & & & & & 0.2 \\
\hline
\end{tabular}


is not nearly so marked as among the youngest speakers. Speakers over 65 also share relatively little with other age groups, a finding which is explicable by their tendency to use obsolete or archaizing words, not common among younger speakers. The middle groups tend to have high rates with themselves and their immediate neighbors. This is especially so for the middle age groups, which we saw to contain speakers using fewer idiosyncratic and nonce terms than the others, and more established borrowings. This is supported by the finding that all of the other age groups also have the highest sharedness rates with those in the middle age group; they tend to use the established, or basic, loanwords in common with them.

In fact, there are two cross-cutting effects here. All age groups actually share more with immediately neighboring groups than with remote ones, an effect representing the dynamics of loanword sharedness and diffusion. This could either indicate that speakers tend to communicate most with others of similar age groups, or simply reveal an apparent time effect whereby those acquiring the language at approximately the same time tend to use words current at that time. This result is obscured somewhat by the middle-aged vs. polar group effect, which represents the distribution of nonce and idiosyncratic versus widespread borrowings: the young tend to use nonce borrowings, older speakers obsolete terms, while the middle-aged favor the basic stock of English-origin forms, which they also share with speakers of other ages.

Another systematic pattern, though one with even smaller effects, relates to differences in English proficiency within the sample, as in Table 16. Only the two groups with the least proficiency in English show more internal homogeneity than predicted, or for that matter, more commonalities with each other. The higher-proficiency speakers, who favor nonce (and hence individualistic) borrowing, have low internal homogeneity. Table 16 also suggests that there is a greater tendency for loanwords to circulate between the lower-proficiency groups.

An examination of the sharedness results for the five neighborhoods reveals little consistent patterning, except that the Hull neighborhoods show relatively low commonality with the Ottawa neighborhoods, and

Table 16. Sharedness among language proficiency groups

\begin{tabular}{lllll}
\hline & Low & Mid-low & Mid-high & High \\
\hline Low & 0.6 & 0.5 & 0.0 & -0.4 \\
Mid-low & & 0.5 & 0.1 & -0.4 \\
Mid-high & & & -0.5 & -0.8 \\
High & & & & -0.9 \\
\hline
\end{tabular}


some degree of internal homogeneity, perhaps reflecting the geographical and political separation of Quebec and Ontario. As for occupational class and sex, only very minor deviations from the predicted amount of sharedness were observed.

\subsection{Discussion and conclusions}

Not all the English-origin lexical material in our corpus was analyzed in this study. In line with previous work, and in accordance with our understanding of a borrowing as being a single $\mathrm{L}_{2}$-origin item used in an $\mathrm{L}_{1}$ slot, our operational definition restricted our sample to include only SINGLE English words incorporated into French discourse. Characterization of code switching in Ottawa-Hull (Poplack 1985) as often accompanied by translation, metalinguistic commentary, and other 'flagging' devices further helped eliminate probable single-word code-switches from our sample of borrowings. These attempts to refine the data were motivated by the clearcut conceptual distinction between borrowing, in which an $L_{2}$ lexical item submits to $L_{1}$ morphological and syntactic rules in $L_{1}$ discourse, and code switching, in which each monolingual fragment is lexically, morphologically, and syntactically grammatical in one language.

In French-English bilingualism, however, there are often no morphological or syntactic criteria for determining whether a single lexical item is following English or French rules; noun morphology is most frequently null in both languages, and word order is very similar. Is there any point, then, in attempting to conform to the theoretical distinction between code-switching and borrowing at the single-word level? Evidence from other language pairs (for example, Tamil-English [Sankoff et al. 1986], and Finnish-English [Poplack et al. 1987]), where nominal morphology and/or syntax differs appreciably for $L_{1}$ and $L_{2}$, strongly suggests that code switching and borrowing remain distinct processes, even at the level of the single word. Whereas in code switching, the speaker alternates between one coherent grammar (and lexicon) and another, according to certain predictable syntactic constraints on switch points, in borrowing only one grammatical system is brought into play.

While it is clear that for bilinguals, all $\mathrm{L}_{2}$ content-words are fair game for borrowing, especially nouns and certain other categories, it is equally obvious that only some items are used recurrently, and that a still more restricted set is also used by monolinguals (or, in our corpus, nonfluent bilinguals). Conceptually, the free choice of $L_{2}$ lexical items, which we call nonce borrowing, is somewhat different from repeated use of the same 
item, and even more so from its use by one (possibly monolingual) speaker after having heard it in the $L_{1}$ speech of others. In the latter case we are moving away from the specific concomitants of bilingualism toward more general processes of lexical transmission at the social level, in terms of frequency of use and degree of acceptance. Indeed, most occurrences of borrowing into Ottawa-Hull French involve 'established' loanwords - those in widespread use in the region and already in some sense 'accepted' in the language, if we use dictionary attestations as one gauge of acceptance. The majority ${ }^{35}$ of these are in fact 'international' loanwords, appearing as well in European French sources. The most frequently used forms tend to be of long standing, having entered the lexicon a century or more ago.

In view of this, the methods we have developed in the context of borrowing are equally applicable to detecting and quantifying the introduction of new vocabulary among the younger generation, in specific geographical locales, and in certain social milieux, as well as its spread from an innovating group to neighboring ones and, finally, its eventual obsolescence. The role of environmental variables (here, linguistic loyalty and avoidance of English, the social stigma of 'incorrect' French, the majority vs. minority status of French in the neighborhood) and individual attributes (here, proficiency in English, the tendency to assimilate phonologically) can also be evaluated by the techniques we have adopted, in the study of general lexical dynamics.

The processes involved in the linguistic, as contrasted with the social, assimilation of loanwords are much more specific to the bilingual context. Thus the gradual phonological integration of loanwords is a type of process that does not really play a major role in monolingual lexical innovation, since it necessarily involves other-language elements in a crucial way. Though it proceeds inexorably as the word becomes widespread in the community, phonological integration is subject to complex influences on the level of the individual speaker. On the one hand, speakers who use widespread loanwords tend to produce them with $L_{1}$ phonology. On the other, it is the highly bilingual speakers who tend to use more borrowed tokens and more of each type, including widespread loans, but it is precisely these speakers who show the least tendency to shed their source-language phonology. We could not have distinguished these competing effects without careful statistical analysis of a large data base.

The borrowed lexicon differs from the native vocabulary in the distribution of grammatical categories as well. Borrowed forms show a statistically much stronger preference for the category of nouns, though they are also solidly attested in two other grammatical categories: verbs 
and adjectives. It is only the most innovative speakers, however, who significantly exploit the option of borrowing into categories other than nouns. The question of gender assignment to nonce nouns is only rarely encountered in monolingual discourse and is highly predictable in that context, due to regularities in gender associations with nominalizing suffixes and other French word-formation processes. In the bilingual context, however, it is a recurrent problem, particularly since most English-origin words do not conform to host-language phonological or word-formation patterns. Thus it is striking that consistency in gender assignment occurs relatively early in the borrowing process - an average $4 \%$ rate of gender inconsistency ${ }^{36}$ seems equally pertinent to types with only two gender-marked tokens in our corpus as to types with hundreds.

Plural marking also tends to follow French patterns from an early stage ( $85 \%$ for words used by a single speaker), although here some effect of frequency is discernible.

We also found that all borrowed verbs, frequent or rare, appear fully integrated into the unmarked French conjugation class, while adjectives and adverbs resist morphological integration.

On the syntactic level, integration of borrowings into host-language patterns is virtually categorical. Integration on the phonological level is thus the only clear linguistic differentiator of nonce from widespread borrowing, and that only in a statistical sense. Returning to methodological considerations, we have also shown, through the comparison of these words to other content words internal to unambiguous code-switches to English, that nonce borrowings are phonologically more integrated into French than can be accounted for by speakers' 'French accent'. Of course, some of the words we operationally classified as nonce borrowings are incorrectly assigned to this class. Infrequency of usage may be due not only to the fact that a word is borrowed only momentarily, but also to the relative infrequency in discourse of the referent that the word expresses. Indeed some of our 'nonce' terms are historically attested, another factor correlated with loanword assimilation. Thus it could very well be that true nonce borrowings are on the average even less integrated phonologically than it would seem from our calculations. On the other hand, some of these nonce tokens may properly belong to the conceptually distinct category of single-word code-switches, since our operational definitions cannot entirely exclude this possibility in the French-English context. These two types of misidentification will tend to compensate for each other in their effect on the phonological integration calculations, since rare but attested loanwords will tend to be more and code-switches less integrated than true nonce borrowings.

We can now situate the borrowing process in the general scheme of 
bilingual and monolingual discourse in the Ottawa-Hull French-speaking community. There are basically two distinct ways a bilingual speaker can 'mix' English elements into French discourse. One way, not specifically studied here, is to switch into a monolingually grammatical English sentence or (single- or multiword) sentence fragment, containing no French syntax or morphology. The second is to borrow a single English content word for the nonce, to assign it a French gender if it is a noun, or the appropriate inflections if it is a verb, and possibly, though not necessarily, some aspects of French phonology, and to use it in a French syntactic slot. Once thus used, the borrowed form has a (small) chance of 'catching on', first presumably in the speaker's own discourse, but also in the speech of others, even monolinguals. Thus every nonce borrowing has the potential to become an established loan, but few actually travel the whole trajectory between these two extremes. The degree to which this potential is realized is reflected in at least three types of data - historical persistence, frequency of use, and degree of phonological integration. Morphological and syntactic integration are not relevant to this process of social integration, since they occur at, or in some respects, very soon after, the stage of nonce borrowing. The interactional, demographic, and attitudinal factors which determine whether a borrowing will become widespread are, except at the very beginning when bilingualism plays a key role, the same sorts of influences which govern the relative frequency of elements in the lexicon more generally.

In assessing how these factors could account for the variation in the use of English-origin vocabulary within the Ottawa-Hull community, we first used analysis of variance (ANOVA) to establish the statistical significance of their effects on the various components of a borrowing profile and then examined the significant influences in more detail.

Speakers originating in neighborhoods with the greatest environmental exposure to English, that is, Ottawa residents in general, and those from the West End in particular, were seen to be innovating, as indicated by their elevated rates of idiosyncratic and nonce borrowing, and more indirectly, by consistently higher rates of recently attested or altogether unattested items among their widespread loanwords. On the other hand, Vieux Hull seems rather to be the locus of heightened circulation of integrated loanwords already well attested in other francophone communities.

Use of borrowed vocabulary is more frequent among Hull men compared to women, but this can be attributed to the large proportion of men with a history of work experience in Ottawa.

High occupational status inhibits borrowing rate, and this factor crosscuts other more favorable ones. This explains why Mont Bleu lags behind 
Vieux Hull in borrowing and, similarly, why there is less borrowing in Vanier than in other Ottawa neighborhoods with an equal or lesser number of proficient bilinguals.

Individuals who grew up during the 1960s and later have a pattern of usage of English-origin words different from that of their elders, while a similar discontinuity appears to date approximately from the outset of World War II. Innovations in the basic stock of borrowings are being made by the youngest speakers (aged 15-35) in the community, via whom they are propagated to some extent across immediately adjacent groups and appear eventually to become consolidated in the group of middleaged speakers. It is, however, hardly likely that these age differences actually result from synchronic processes acting differentially on the age groups today. Rather, the evidence suggests that borrowed vocabulary is incorporated readily until the age of 30 or 40 , after which point there is relatively little further change.

The ANOVA enabled us to determine a hierarchy among some of the cross-cutting extralinguistic influences on borrowing. With respect to overall use of loanwords as a proportion of total vocabulary, social class (as measured by occupation) is more important than either environmental effects (that is, neighborhood) or individual attributes (that is, bilingual proficiency). The social-class effect may be equated with normative pressures on speaking 'well'. Loanwords form part of the stigmatized lexicon (whether because speakers are aware of their English origin or for some other reason) and are thus avoided by members of the upper classes, behavior which is entirely reminiscent of the classic cases of sociolinguisic variation familiar in the literature.

Contrary to what is predicted by some theories, bilingual proficiency is ot an important influence on overall rate of borrowing. Thus, regardless If a speaker's linguistic capacity to access other-language lexical items, he :onforms to the tendencies prevalent in his speech community. If he esides in an area in which borrowing is common, we may predict that sorrowings will constitute a larger proportion of his total vocabulary han if he lives elsewhere, providing, of course, his social circumstances do tot militate against such usage.

Yet when we examine the pattern of borrowing with respect to roportion of nonce words, we find that the factor of social class has no xplanatory power, in contrast to its preeminent influence on overall rate. Jiven the consistent associations between high proficiency in English and ropensity toward nonce borrowing, it might have been reasonable to ssume that bilingual ability was the key predictor of borrowing pattern. iut although individual bilingual proficiency does appear to have a ystematic effect, because the most proficient English speakers are able to 
access their greater knowledge of $\mathrm{L}_{2}$ for nonce and idiosyncratic borrowings, the environmental influence is paramount. The norms of the community override individual abilities. This striking finding, not previously reported in the literature, must be interpreted as showing that behavior with respect to use of borrowings is ACQUIRED, and not merely a function of lexical need. If it were otherwise, individual competence would outweigh the other factors. Instead, both borrowing rates and patterns are seen to correspond to wider environmental norms, evidenced as sanctions against (elevated rates of) use of borrowed words, or simply as a community-level tendency toward a particular pattern of use. Though this has not been studied systematically, it is most likely that these are precisely the sorts of pressure that are responsible for an individual's relative lexical conformity with his speech community insofar as monolingual speech is concerned. We have already observed that synchronically, nonce and established borrowing are two distinct processes. Only the former constitutes 'active' borrowing, during which lexical items are drawn directly from English and not transmitted via other francophones. Our results indicate that borrowing, especially nonce borrowing, resembles code switching in that it must be a community MODE (Poplack 1980) in order to gain any real currency. An individual's personal ability is operative but is mediated by the norms of his speech community.

Received 30 March 1987

University of Ottawa

Revised version received

8 September 1987

Université de Montréal

University of Ottawa

\section{Notes}

- The research reported here is part of a larger project on sociolinguistic aspects of language contact in the Ottawa-Hull region, generously supported by a grant to Poplack from the Social Sciences and Humanities Research Council of Canada. This work would have been inconceivable without the (occasionally) cheerful cooperation of the project members, who have invested innumerable hours since 1982 in locating, coding, checking, correcting, and computerizing these elusive data on borrowing. We are particularly grateful to Sali Tagliamonte, Carole Lefebvre, Mélanie Wodicka, Pierre Lainey, and Marie Labelle. We thank Edouard Beniak, Raymond Mougeon, and R. LePage for helpful comments. The expert preparation of the text is due to Marguerite Trudel-Maggiore. Correspondence address: Dr. Shana Poplack, Department of Linguistics, University of Ottawa, 78 Laurier E., Ottawa, Ontario K1N 6N5, Canada.

1. Our corpus contains nearly two and one half million words.

2. As ascertained, respectively, by the number of English-mother-tongue claimants in 
each, according to 1970 census figures, and their location in anglophone Ontario or francophone Quebec.

3. The latter three factors were not criteria for sample constitution. All speakers were coded as belonging to one of six age groups ranging from 15 to 90 ; one of the five neighborhoods: Vanier, Basse-Ville, or the West End in Ottawa, and Vieux Hull or Mont Bleu in Hull; one sex category: women or men; one of four occupational groups: unskilled laborers and the unemployed, blue-collar workers, sales and service personnel, and professionals; one of three levels of educational attainment: primary, secondary, or higher; and one of four levels on an index of English proficiency calculated from speakers' self-reports of their English competence and usage in various situations and domains.

4. Full details of sample selection and corpus construction may be found in Poplack (i.p.).

5. In general, we will adhere to the usage of 'loanword' in the specific sense of a borrowing that has achieved some degree of currency.

6. Codes identify speaker and line number of his/her utterance.

7. In previous studies (Poplack 1980; Sankoff and Poplack 1981), single-word codeswitches of grammatical categories not susceptible to borrowing were detected, such as single $L_{2}$ pronouns or articles in $L_{1}$ discourse.

8 Calques, or semantic extensions (such as citron 'lemon', as in [a]), were excluded from this study, as there can be no question of their (linguistic) integration, given that they are already French words, with the exception of single-word French-English homographs used in English senses (such as charger, as in [b].)

a. Mais quand tu vas l'avoir acheté, c'est un vrai citron, ton char. (001/735)

'But when you've bought it, it's a real lemon, your car.'

b. Le bon Dieu, il a jamais chargé une cenne pour baptiser un enfant. (079/1323)

'The good Lord never charged a cent to baptize a child.'

Five hundred and fifty-seven place names were also excluded from the final analyses, although they had a current French equivalent (such as Friel Street for rue Friel), given that proper nouns do not necessarily participate in the same processes of integration as do common nouns.

9. Actually, two versions of the data file were constructed. In the first, if a word occurred as two or more parts of speech, separate entries were made for each one. This file was used only for studying the distribution of parts of speech, since for other purposes it would have given an inflated impression of the number of truly distinct types. Thus, in the second data file, the data were more thoroughly lemmatized, grouping words with a common root, regardless of part of speech and slight differences in meaning. In this analysis, the verb tougher 'to tough it out', for example, would have been grouped with the adjective, noun, and interjection tough and counted as a single type.

10. The sources consulted were Glossaire franco-canadien (Dunn 1880); Dictionnaire canadien-français (Clapin 1894); Dictionnaire de nos fautes contre la langue française (Rinfret 1896); Le parler populaire des canadiens français (Dionne 1909); Glossaire du parler français au Canada (Société du parler français au Canada 1930); Le ramage de mon pays (Barbeau 1939); Les anglicismes au Québec (Colpron 1970); Néologismescanadianismes (Clas 1976); Dictionnaire nord-américain de la langue française (Bélisle 1979); and Trésor de la langue française au Québec: volume de présentation (Poirier 1985). We also consulted a data base of nonstandard forms extracted from the news magazine L'Actualité (1976-1977) by André Lapierre.

11. Of course, some words in widespread use may not occur at all or only show up as nonce or idiosyncratic because the corresponding topics were not foci of conversation (such 
as revolver, kidnapper; see also Mougeon et al. 1985b). However, the size of the data base tends to attentuate this problem.

12. In the analyses that follow we focus on the dichotomy between widespread loans and nonce borrowings. We only report results for recurrent and idiosyncratic borrowings when these differ from those for the former categories.

13. The results of the lemmatized versus unlemmatized analyses (discussed in note 8) across all factors were identical except for consistent rate differences due to the different input files: for example, the rate of nonce or idiosyncratic borrowings is always lower in the lemmatized data, while the rate of frequent borrowings is higher. Here and in what follows, we report the results of the analysis of the lemmatized data set, except where we make specific reference to the behavior of the different grammatical categories. It should be noted, however, that the results do not differ appreciably from those on the unlemmatized data.

14. In terms of our arbitrary, though rather severe, criterion for established or WIDESPREAD loanwords: spontaneous use by more than ten speakers.

15. Additional divisions included religion and superstition, cigarettes and alcohol, health, housing, nature, travel, justice, love/marriage/friendship and related matters, qualifiers (things), qualities and attributes (persons), technological and work-related terms, business, feelings and emotions.

16. The texts analyzed were selected from a representative subsample of 14 informants. Intraindividual variation in distribution of grammatical categories, despite differences in age, sex, and neighborhood of residence within the subsample of speakers, was so minimal as to obviate the reed for additional data.

17. Counting personal, deictic, and existential pronouns together.

18. It is doubtful whether the latter should be counted as a grammatical category at all, considering their fossilized nature and structural freedom from the rest of the utterance.

19. Of the various hierarchies of borrowability proposed in the literature the one we present is most similar to that proposed by Haugen for Norwegian. The wide-ranging proposal for a hierarchy of borrowability in Muysken (1980), including prepositions, determiners, pronouns, clitics, and complementizers, either must be the result of not distinguishing between code switching and momentary and established borrowings, or else may be characteristic of certain types of extreme borrowing situations, such as pidginization or relexification.

20. All words with ambiguous gender markers (such as un or une 'a' [Barbeau et al. 1982], cet( $t e$ ) 'this' in prevocalic position) were excluded from these calculations.

21. Status as lexicalized plural in the source language has no bearing on the ultimate rendition of the word in the recipient language. Comics is always pronounced [k $\wedge \mathrm{mIk}]$; the single occurence of mumps, [m $\Lambda \mathrm{mps}$ ]. Jeans and shorts, despite being widespread (48 and 30 speakers respectively) and well established are truly variable. Jeans tends to be inflected with $[\mathrm{z}](67 \%)$, while shorts tends to receive $[\varnothing](57 \%)$.

22. One example showed English word order:

Il lui ont donné un soixante cennes raise [raise de soixante cennes]. (014/174)

'They gave her a sixty-cent raise.'

23. Even this word has an unusual status in Canadian French. Though quite old (attested before 1900), it can by no means be considered to have achieved full acceptance in the language, retaining full identification as an English word. Indeed, a native equivalent, gouret, was introduced to replace it by 1909 (Aleong 1981). This neologism appears to have met with limited acceptance (and much ridicule) among the francophone 
populace and occurs in the Ottawa-Hull corpus only in mocking those who speak 'too well'. The publicity surrounding the word hockey is surely responsible for speakers' knowledge that on using it, they are uttering an 'English' word (in contrast to, say, grocerie), which in turn may explain its variable renditions as more Frenchlike than Englishlike. "'

24. The affricates [c̆] and [0] were also considered ambiguous as to language membership since they occur in numerous established and widespread loanwords in which the other segments have been completely integrated into French phonology, such as watcher, chum, lunch, check, job.

25. This is similar to some of the measures proposed by Mackey (1971) but based on real, rather than idealized target productions.

26. See section $\mathbf{5 . 0}$ and note 28 .

27. We did not adjust these figures to take into account the considerable variation in interview length (2-5 hours), since this variation is not correlated with any of the sociodemographic factors, and especially since only the NUMBER of borrowed tokens could be expected to be directly proportional to interview length, rather than any of the rates and percentages we will be using.

28. To avoid empty cells in the ANOVA procedure, three of the independent variables were recoded in terms of binary distinctions only: Ottawa vs. Hull, the lowest three age groups vs. the highest three, and the lower two English proficiency groups vs. the higher two. A three-way distinction was maintained for occupational class, resulting from combining skilled workers with sales and service personnel. For the same reason, five- or four-way ANOVA was not used; rather various combinations of three factors were tried to see which might be significant and to reveal any interactions. These analyses showed that, with few exceptions, only one or two factors were significant for any particular dependent variable, and hence that higher-order analyses would be unlikely to provide any additional insight.

29. This contrast is not merely a mirror-image effect, as there are many loanwords of intermediate frequencies between the two polar categories of nonce and widespread borrowings.

30. Both have appreciably the same number (less than 10\%) of English-mother-tongue claimants, though Vieux Hull does have a somewhat higher proportion of proficient English speakers. This fact should not affect established, or recurrent, loanword usage, however, since access to English is not related to their acquisition. We confirm this claim in what follows.

31. We chose $40 \%$ as a general cut-off point (for example, twice as many words concentrated in a neighborhood as would be expected if the words were distributed equally among all five of them) because, due to the large number of subdivisions (six age groups, five neighborhoods, etc.) very few words are concentrated in a group in higher proportions $(60 \%$ or $80 \%)$.

32. Percentages will not add up to 100 because we have not included all categories of attestation.

33. Note that this calculation, based on the loanwords statistically associated with each group, of necessity excludes rare borrowings, particularly nonce and idiosyncratic, which are more likely to consist of nouns and adjectives $(86 \%)$ than widespread words $(72 \%)$. Because highly bilingual and other innovative speakers make greater use of these rare borrowings, their inclusion would have masked the relative grammatical diversity in their choice of more widespread borrowings. Indeed, as mentioned in section 4.1, there is no significant variation across subgroups of the population when the mass of rare borrowings is included in the study of their distribution across 
grammatical categories. This remark is pertinent to all our subsequent discussion of differential preferences for particular parts of speech.

34. Were the random model strictly true, the expected number of borrowed types in common for two individuals with totals of $\mathrm{M}$ and $\mathrm{N}$ borrowed tokens respectively would be the sum, over all different borrowed types $T$ in the corpus, of $\left(1-[1-P(T)]^{M}\right)$ $\left(1-[1-P(T)]^{N}\right)$ where $P(T)$ is the number of occurrences of type $T$ in the corpus divided by the grand total of all borrowings. As might be expected, however, those individuals with at least one token of $\mathrm{T}$ are more likely to have additional tokens of $\mathrm{T}$ than would be predicted by the random model. Thus, there are fewer individuals overall using $T$, a fact that we corrected for by reducing $P(T)$ to $2 / 3 P(T)$ in the above formula; the factor $2 / 3$ is the correction which brings the predicted average sharedness of pairs of speakers in line with the observed value.

35. As inferred from the subsample on which we based our study of attestations.

36. As mentioned above, gender assignment shows some variability in Ottawa-Hull French.

\section{References}

L'Actualité (1976-1977). L'Actualité: le magazine national de la famille canadienne française. Montréal: Le Maclean.

Aleong, S. (1981) Lexical variation in Quebec French ice hockey terminology: a historical perspective. In D. Sankoff and H. J. Cedergren (eds.), Variation Omnibus, 463-471. Edmonton: Linguistic Research.

Arndt, W. (1970). Nonrandom assignment of loanwords: German noun gender. Word 26 (2), 244-253.

Baetens Beardsmore, H. (1971). A gender problem in a language contact situation. Lingua 27, 141-159.

Barbeau, P., Ducharme, C., and Valois, D. (1982). D'un usage particulier du genre en canadien-français: la féminisation des noms à initiale vocalique. Canadian Journal of Linguistics 27 (2), 103-133.

Barbeau, V. (1939). Le ramage de mon pays: Le franfais tel qu'on le parle au Canada. Montréal: Valiquette.

Bélisle, L.-A. (1979). Dictionnaire nord-américain de la langue française. Montréal: Beauchemin.

Bourdieu, P., and Boltanski, L. (1975). Le fétichisme de la langue. Actes de la Recherche en Sciences Sociales (Juillet) 4, 2-32.

Bowen, J. D. (1975). Adaptation of English borrowing. In E. Hernandez-Chavez, A. D. Cohen, and A. F. Beltramo (eds.), El lenguaje de los chicanos. Washington: Center for Applied Linguistics.

Clapin, S. (1894). Dictionnaire canadien-français. Québec: Les Presses de l'Université Laval.

Clas, A. (1976). Néologismes - Canadianismes: Matériaux pour l'étude du français au Canada. Montréal: Les Presses de l'Université de Montréal.

Colpron, G. (1970). Les anglicismes au Québec: répertoire classifié. Montréal: Beauchemin.

Dionne, N.-E. (1909). Le parler populaire des Canadiens français. Québec: Les Presses de l'Université Laval.

Dunn, O. (1880). Glossaire franco-canadien. Québec: Les Presses de l'Université Laval.

Hasselmo, N. (1969). On diversity in American Swedish. Svenska Landsmål och Svenskt Folkliv, 53-72. 
Haugen, E. (1950). The analysis of linguistic borrowing. Language 26, 210-231.

-(1956). Bilingualism in the Americas: A Bibliography and Research Guide. American Dialect Society Monograph 26. University: University of Alabama Press.

-(1969). The Norwegian Language in America. Bloomington: University of Indiana Press.

Kachru, B. (1978). Toward structuring code-mixing: an Indian perspective. International Journal of the Sociology of Language 16, 28-46.

Labov, W. (1970). The study of language in its social context. Studium Generale 23, 30-87.

-(1971). Some principles of linguistic methodology. Language in Society 1, 97-120.

-(1984). Field methods of the project on linguistic change and variation. In J. Baugh and J. Scherzer (eds.), Lamguage in Use: Readings in Sociolinguistics, 28-54. Englewood Cliffs, N.J.: Prentice-Hall.

Lefebvre, C. (1984). Grammaires en contact: définition et perspectives de recherche. Revue québecoise de linguistique 14 (1), 11-49.

LePage, R., and Tabouret-Keller, A. (1980). Acts of Identity. Cambridge: Cambridge University Press.

Mackey, W. F. (1970). Interference, integration and the synchronic fallacy. Georgetown University Round Table on Languages and Linguistics 23, 195-227. Washington, D.C.: Georgetown University Press.

-(1971). La distance interlinguistique. Québec: Les Presses de l'Université Laval.

Madaki, R. (1983). A linguistic and pragmatic analysis of Hausa-English code-switching. Unpublished Ph.D. dissertation, University of Michigan.

Mougeon, R., Beniak, E., and Valois, D. (1985a). Variation in the Phonological Integration of Loanwords in a Bilingual Speech Community. Toronto: Centre for Franco-Ontarian Studies.

—, Beniak, E., and Valois, D. (1985b). Répertoire classifié des emprunts lexicaux à l'anglais dans le français parlé de Welland (Ontario). Toronto: Centre for Franco-Ontarian Studies.

-, Beniak, E., and Valois, D. (1985c). Issues in the Study of Language Contact: Evidence from Ontarian French. Toronto: Centre for Franco-Ontarian Studies.

Muysken, P. (I980). Half-way between Spanish and Quechua: the case for relexification. In A. Highfield and A. Valdman (eds.), Historicity and Change in Creole Studies. Ann Arbor, Mich.: Karoma.

-(1984). The state of the art in interlinguistics. Revue québecoise de linguistique 14 (1), 49-77.

Nash, R. (1970): Spanglish: Language contact in Puerto Rico. American Speech 45 (3/4), 223-233.

Norman, W. (1976). Quiché text. International Journal of American Linguistics 1 (1), 40-60.

Poirier, C. (director) (1985). Trésor de la langue française du Québec: Volume de présentation. Ste-Foy: Presses de l'Université Laval.

Poplack, S. (1980). 'Sometimes I'll start a sentence in Spanish y termino en español': toward a typology of code-switching. Linguistics 18, 581-618.

-(1985). Contrasting patterns of code-switching in two communities. In H. J. Warkentyne (ed.), Methods V: Papers from the V International Conference on Methods in Dialectology, 363-386. Victoria: University of Victoria Press.

-(i.p.). The care and handling of a mega-corpus. In R. Fasold and D. Schiffin (eds.), Language Variation and Change. Amsterdam: Benjamins.

-, and Miller, C. (1985). Political and interactional determinants of linguistic insecurity. Paper presented at NWAVE XIV.

-, Pousada, A., and Sankoff, D. (1982). Competing influences on gender assignment: variable process, stable outcome. Lingua $57,1-28$. 
-, and Sankoff, D. (1984). Borrowing: the synchrony of integration. Linguistics 22, 99-135.

-, Wheeler, S., and Westwood, A. (1987). Distinguishing language contact phenomena: evidence from Finnish-English bilingualism. In P. Lilius et al. (eds.), Proceedings of the VI International Conference on Nordic and General Linguistics. Helsinki: University of Helsinki Press.

Rinfret, R. (1896). Dictionnaire de nos fautes contre la langue franfaise. Montréal: Cadieux et Derome.

Robert, P. (1986). Petit Robert: Dictionnaire alphabétique et analogique de la langue française. Paris: Société du nouveau Littré.

Romaine, S. (1985). The syntax and semantics of the code-mixed compound verb in Panjabi/English bilingual discourse. Paper presented at the Georgetown University Round Table on Languages and Linguistics.

Roy, M.-M. (1981). Les conjonctions but et so dans le français de Moncton: Les contraintes linguistiques. In D. Sankoff and H. Cedergren (eds.), Variation Omnibus, 429-437. Edmonton: Linguistic Research.

Sankoff, D., and Poplack, S. (1981). A formal grammar for code-switching. Papers in Linguistics 14 (1) 3-46.

-, Poplack, S., and Vanniarajan, S. (1986). The Case of the Nonce Loan in Tamil. Centre de recherches mathématiques, Technical Report 1348. University of Montreal.

-, and Sankoff, G. (1973). Sample survey methods and computer-assisted analysis in the study of grammatical variation. In R. Darnell (ed.), Canadian Languages in their Social Context, 7-64. Edmonton: Linguistic Research.

Sankoff, G. (1974). A quantitative paradigm for the study of communicative competence. In R. Bauman and J. Scherzer (eds.), Explorations in the Ethnography of Speaking, 18-49. Cambridge: Cambridge University Press.

Smith-Stark, T. (1976). Jilotepequeño Pocomam texts. International Journal of American Linguistics 1 (1), 72-87.

Société du parłer français au Canada (1930). Glossaire du parler français au Canada. Québec: L'action sociale.

Tesnière, L. (1939). Phonologie et mélange des langues. Travaux du cercle linguistique de Prague 8, 83-93.

Trager, L. (1944). Spanish and English loanwords in Taos. International Journal of American Linguistics 10, 146-158.

Wartburg, W. von (1957). Französisches Etymologisches Wörterbuch: eine Darstellung des galloromanischen Sprachschatzes. Basel: Zbinden.

Weinreich, U. (1968). Languages in Contact. The Hague: Mouton.

Whitney, W. D. (1881). On mixture in language. Transactions of the American Philosophical Association 12, 1-26. 